\title{
Rapid re-expression of CD133 protein in colorectal cancer cell lines in vitro and in vivo
}

\author{
Susann Peickert ${ }^{1, *}$, Julia Waurig ${ }^{1, *}$, Claudia Dittfeld ${ }^{1, *}$, Antje Dietrich ${ }^{1}$, Yvette Garbe $^{1}$, Lydia Kabus ${ }^{1}$, \\ Michael Baumann ${ }^{1,2}$, Marian Grade $^{3}$, Thomas Ried ${ }^{4}$ and Leoni A Kunz-Schughart ${ }^{1}$
}

Studies related to the cancer stem cell hypothesis are challenging because of the imperfect tools to identify cell populations of interest and controversy on the usefulness of established cancer cell lines. We previously found CD133 to not be selective for a tumor-propagating or radioresistant population in a near-diploid, microsatellite-instable colorectal carcinoma (CRC) cell line. Because of discrepant literature data, we herein systematically analyzed the behavior of microsatellite-stable cell line subpopulations reflecting the more frequent carcinogenesis pathway in spontaneous CRC. $\mathrm{CD}_{133^{+}}$and $\mathrm{CD} 133^{- \text {llow }}$ populations were isolated by fluorescence-activated cell sorting and further processed. HT29 and SW620 cells were studied in detail in monolayer and/or spheroid culture assays and upon subcutaneous injection in NMRI (nu/nu) mice using a limiting dilution approach. CD133-/low HT29 cells showed a significantly lower clonogenic survival and reduced spheroid formation capacity than their $\mathrm{CD}_{133^{+}}$counterparts. However, the cell populations neither differed in growth kinetics and response to treatment in vitro nor in tumor formation capacity when injecting as low as 10 cells. CD133 - /low $\mathrm{HT} 29$ cells rapidly re-expressed CD133 protein in vitro and in vivo as shown by flow cytometry and/or western blot analyses, and they also showed a particular survival benefit under tissue normoxic conditions. In contrast, $\mathrm{CD} 133$ protein in the $\mathrm{CD} 133^{+}$population was quite stable throughout culturing. The observation of CD133 re-expression and lack of difference in tumor take rate of subpopulations was confirmed in SW620 cells. Here, we found cell density to affect CD133 re-expression in the CD133- ${ }^{-}$-sorted population. And even SW480 cells, classified as a CD133- cell line, presented some CD133 protein on their surface upon in vivo engraftment. We conclude that (i) CD133 protein expression shows high plasticity in CRC cell lines, and (ii) in vitro CD133 status on the cell surface neither determines tumorigenic potential nor CD133 profile in vivo.

Laboratory Investigation (2012) 92, 1607-1622; doi:10.1038/labinvest.2012.124; published online 10 September 2012

KEYWORDS: cancer stem cell hypothesis; CD133 protein; colorectal cancer cell line; 2-D culture; 3-D culture; radio-/chemotherapy; xenograft

Colorectal carcinoma (CRC) is one of the three most common malignant diseases and the second leading cause of cancerrelated deaths. ${ }^{1-3}$ More than $40 \%$ of CRC are located in the rectum. Although the local recurrence rate of rectal carcinoma is less than $10 \%$ after preoperative radiotherapy/ chemoradiotherapy and surgery based on total mesorectal excision, the development of distant metastases leads to a high rate of treatment failure of $30-35 \% .{ }^{4}$ The hypothesis that certain subpopulations, frequently termed tumor-initiating, tumor-propagating or cancer stem cells (TIC/TPC/CSC), are resistant to classical treatment strategies and responsible for recurrence and metastasis of the disease is under intense investigation in CRC. ${ }^{5-12}$ Several cell surface markers have been described to enrich for TIC/TPC/CSC subpopulations from CRC, such as CD133, CD44 or CD166.,12-18 In 2007, two groups independently described CD133-positive CRC cells from primary material but not their negative counterparts to be capable of producing tumors in mouse models. ${ }^{19,20}$ In one of these studies, CD $133^{+}$subpopulations could be maintained in vitro as spheres under serum-free conditions, but CD133 expression was downregulated when cultured adherently upon

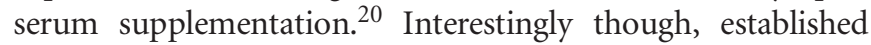

\footnotetext{
${ }^{1}$ OncoRay—National Center for Radiation Research in Oncology, Medical Faculty Carl Gustav Carus, Dresden University of Technology, Dresden, Germany; ${ }^{2}$ Department of Radiation Oncology, Medical Faculty and University Hospital Carl Gustav Carus, University of Technology, Dresden, Germany; ${ }^{3}$ Department of General and Visceral Surgery, University Medicine Göttingen, Göttingen, Germany and ${ }^{4}$ National Cancer Institute, National Institutes of Health, Bethesda, MD, USA

Correspondence: Professor Dr LA Kunz-Schughart, OncoRay—National Center for Radiation Research in Oncology, Medical Faculty Carl Gustav Carus, Dresden University of Technology, Fetscherstraße 74, PF 86, Dresden 01307, Germany.

"These authors contributed equally to this work.

Received 16 March 2012; revised 19 July 2012; accepted 25 July 2012
} 
CRC cell lines routinely grown as adherent monolayers under serum-containing conditions show a highly variable CD133 surface expression. ${ }^{21}$ The argument that cell lines no longer reflect the original in vivo tumor cell geno- and/or phenotype is legitimate but challenges all previous and ongoing functional studies based on such cancer cell lines notwithstanding that they are tumorigenic in mouse models and have indeed led to numerous insights in cancer cell biology. In addition, primary and secondary anti-tumor treatment testings are not routinely performed with primary cells from patients' material but most frequently relies on established cell lines. Therefore, it is of utmost interest to further verify the expression profiles of putative CSC biomarkers not only in primary tumor cells but also in established cell lines and to evaluate the tumorigenic potential and therapy response of CD133-positive vs CD133-negative cell lines and subpopulations.

We previously found $\mathrm{CD}_{133^{+}}$and $\mathrm{CD}_{133^{-}}$subpopulations of the near-diploid and microsatellite-instable CRC cell line HCT-116 to neither differ in clonogenic cell survival or radioresponse in vitro nor in tumorigenic capacity. ${ }^{21}$ In contrast, HT29 were described by others to show a CD133related CSC behavior based on small cohort animal experiments $^{22}$ and characteristics consistent with those of CSCs are also stated for the $\mathrm{CD}_{133^{+}}{ }^{+}$subfraction of SW620 cells, although no difference in tumor formation rate but in tumor size was observed. ${ }^{23}$ HT29 and SW620 are aneuploid or hyperdiploid, respectively, with a microsatellite-stable, chromosome instable (MSS/CIN) phenotype, which is seen in the majority (about 85\%) of spontaneous CRC. ${ }^{24}$ We therefore hypothesized that the difference to our HCT-116 data may relate to the different carcinogenesis pathways. The current study was thus performed to verify the presence of a CD133-associated CSC phenotype in MSS/CIN CRC cell lines. The particular aim was a subsequent systematic comparison of the in vitro and in vivo behavior of $\mathrm{CD} 133^{+}$ vs $\mathrm{CD} 133^{- \text {llow }} \mathrm{CRC}$ cell line subpopulations. The results are striking, allude to various highly relevant methodological inconsistencies related to CD133 detection and isolation of subpopulations with differential CD133 expression, and indicate a high plasticity in CD133 positivity.

\section{MATERIALS AND METHODS}

\section{Cell Lines and Culture Routines}

Six colon carcinoma cell lines purchased from the ATCC (American Type Culture Collection, Manassas, USA) were studied (HCT-116-MSI; HT29, SW620, SW480, SW1417, LS1034-all MSS, see also Supplementary Table 1). Cell lines were free of mycoplasma as tested using a PCR Mycoplasma Kit (Applichem, Germany) and checked for correct genetic profile. Routine verification of cell line purity and clonality was detailed earlier for HCT-116 cells. ${ }^{21}$ Authenticity of cell lines was confirmed by microsatellite analyses at the Institute of Legal Medicine (Dresden University of Technology) using the commercial multiplex PCR kits Mentype NonaplexQS
Twin (Biotype, Germany) and PowerPlex 16 (Promega Corporation, USA). Amplicons were detected by capillary electrophoresis in denaturing polymer POP4 in an ABI 310 sequencer (Perkin-Elmer, USA) according to the manufacturer's instructions.

Cells were routinely grown in DMEM (Dulbecco's Modified Eagle Medium, PAN Biotech, Germany) containing antibiotics, phenol red, $25 \mathrm{mM}$ HEPES (4-(2-hydroxyethyl)1-piperazineethanesulfonic acid), $5 \mathrm{mM}$ glucose, $1 \mathrm{mM}$ sodium pyruvate and $4 \mathrm{mM}$ L-glutamine and supplemented with 10\% FCS (Fetal Calf Serum, PAN Biotech). Culturing was performed at $37^{\circ} \mathrm{C}$ in a humidified $5-8 \% \mathrm{CO}_{2}$ in air atmosphere. For experimental setup, cells were thawed from frozen stocks and passaged at least twice but no more than 10 times in 2-D culture before use. Exponential monolayer cultures were dissociated by enzymatic and mechanic means using a $0.05 \%$ trypsin $/ 0.02 \%$ EDTA (Ethylenediaminetetraacetic acid) in PBS (Phosphate-buffered saline, PAN Biotech) solution to obtain single-cell suspensions for cell transfer, flow cytometric analyses and cell sorting. Cell numbers and volumes were monitored with a Casyl cell analyzer system (Roche Innovatis).

\section{Flow Cytometric Analyses and Fluorescence-Activated Cell Sorting (FACS)}

CD133 cell surface expression was analyzed in single-cell suspensions from monolayer and spheroid cultures as well as from HT29, SW480 and SW620 xenografts. An advanced anti-CD133 staining protocol was applied as described earlier. ${ }^{21}$ Briefly, cells were incubated for $30 \mathrm{~min}$ in the dark at $4^{\circ} \mathrm{C}$ with a PE (phycoerythrin)-conjugated anti-CD133 antibody (CD133/1-PE or isotype, Miltenyi Biotec) diluted 1:100 in PBS containing 0.5\% FCS and 2 mM EDTA followed by signal enhancement via a two-step FASER series (Fluorescence Amplification by Sequential Employment of Reagents) according to the manufacturer's instructions (Miltenyi Biotec). Cell suspensions originated from xenograft tumors were also co-stained with an anti-human CD326-FITC (fluorescein isothiocyanate) antibody (dilution 1:25; Miltenyi Biotec) to discriminate human epithelial and mouse stromal cells. Adequate isotope antibodies at equivalent working concentrations served as controls. Propidium iodide was added at $2 \mu \mathrm{g} / \mathrm{ml}$ per sample directly before measurement to discriminate membrane-defect cells. CD133 profiles were recorded with a FACScan or a FACSCanto $^{\mathrm{TM}}$ II flow cytometer (BD Biosciences, USA); signals of a minimum of $2 \times 10^{4}$ events or $1 \times 10^{4}$ viable cells of interest were collected per sample.

Intracellular CD133 positivity was determined in cell suspensions (LS1034) pre-stained for membraneous CD133 as described. These cells were fixed and permeabilized using freshly prepared $4 \%$ paraformaldehyde in PBS, followed by two washing steps with PBS containing $1 \%$ FCS and a $20 \mathrm{~min}$ exposure to sterile permeabilization buffer $(0.05 \%$ saponin in $\mathrm{PBS} / 1 \%$ FCS buffered with $0.12 \%$ HEPES) at room 
temperature (RT). Membrane-permeabilized cells were then exposed to the mouse monoclonal W6B3C1 antibody (Miltenyi Biotec) at a dilution of 1:100 in permeabilization buffer or equivalent concentration of an isotype control (Immunotools). An Alexa-488-conjugated goat-anti-mouse secondary antibody (1:100; Invitrogen) was applied for visualizing intracellular $\mathrm{CD} 133$ in the $\mathrm{CD} 133^{- \text {low }_{\text {-sorted }}}$ LS1034 fraction. Cells were washed twice and kept on ice between the incubation steps and were finally resuspended at a concentration of $1 \times 10^{6}$ cells in $0.5 \mathrm{ml} \mathrm{PBS} / 1 \%$ FCS for flow cytometric analysis.

For FACSorting using a FACSAria (BD Biosciences), single-cell suspensions from exponentially grown monolayer cultures were stained accordingly and resuspended at a concentration of $(0.5-1) \times 10^{7}$ cells $/ \mathrm{ml}$ in PBS plus $2 \mathrm{mM}$ EDTA. Sorted subpopulations were routinely reanalyzed by flow cytometry for purity; cell numbers and quality were reassessed via the Casyl cell analyzer before any in vitro culturing or in vivo implantation.

\section{Western Blot Analysis}

Whole cell protein was extracted using RIPA buffer $(1 \times$ PBS, $1 \%$ Nonidet P40, $0.5 \%$ Sodiumdeoxycholat, $0.1 \%$ SDS) after addition of $0.1 \mathrm{M}$ PMSF and a 1:100 protease inhibitor cocktail (P2714, Sigma-Aldrich, Germany). Protein content was determined via the BCA Protein Assay Kit (Pierce, Germany) as described by the manufacturer and aliquots were stored at $-80^{\circ} \mathrm{C}$. Two antibodies were used to visualize $\mathrm{CD} 133$ protein. An extracellular domain (AC133) is recognized by the anti-human W6B3C1 antibody (Miltenyi Biotec), which was applied in a TBS-buffered system, whereas the Ab19898 anti-human CD133 antibody (Abcam, UK) in PBS-buffered solutions binds to the intracellular C-terminus of CD133. Proteins were separated by 10\% SDS-PAGE and transferred onto PVDF membranes (Millipore, Germany), which were blocked overnight in TBS and PBS, respectively, containing $0.1 \%$ Tween 20 and $5 \%$ milk powder. After washing three times with the respective buffers supplemented with $0.1 \%$ Tween 20 , membranes were exposed to either the mouse monoclonal W6B3C1 antibody (1:100 diluted in blocking buffer) or the rabbit polyclonal anti-human CD133 antibody Ab19898 (1:100 diluted in PBS containing 0.1\% Tween20) for $1 \mathrm{~h}$ at RT. Membranes were then washed, incubated with secondary anti-mouse or anti-rabbit immunglobulin/HRP (dilution 1:5000, $1 \mathrm{~h}$, RT; Dako, Germany), subjected to western blotting luminol reagent (Santa Cruz, Germany) for $1 \mathrm{~min}$ and film exposure for $10 \mathrm{~min}$. $\beta$-Actin was probed as control using the monoclonal antibody Ab6276-100 (Abcam, UK) in a TBS-buffered system (1:2000 in TBS containing 3\% milk powder) and the secondary system as described. Semiquantitative analysis of $\mathrm{CD} 133$ protein relative to $\beta$-actin was performed with ImageJ Software (http://rsbweb.nih.gov/ij/); the CD133 expression of originally distributed cell populations was set as $100 \%$.

\section{2-D assays of FACSorted Subpopulations}

Subpopulations of selected cell lines, sorted according to their CD133 expression, were studied in 2-D culture with respect to colony formation capacity, growth behavior and CD133 profile. For colony formation assays (CFA), 400 FACSorted cells were seeded into each well of a six-well plate in standard DMEM and incubated under routine culture conditions for a period of 17 days. Cells were then stained with $0.5 \%$ crystal violet or $0.05 \%$ Coomassie Brilliant Blue and plating efficiencies were determined by manually counting colonies containing more than 50 cells under an AxioVert200 microscope (Carl Zeiss MicroImaging GmbH, Germany). A minimum of three wells per condition and subpopulation, respectively, was analyzed. To evaluate the impact of tissue normoxic conditions on colony formation of HT29 cells, adherent cells were relocated $4 \mathrm{~h}$ after plating to an Invivo300 Incubator (IUL, Germany) to be kept in a humidified $5 \% \mathrm{CO}_{2}$ atmosphere at $4 \%$ oxygen.

A total of $1 \times 10^{4} \mathrm{CD}_{133^{+}}, \mathrm{CD} 133^{- \text {low }}$ and original (run-through sorter) HT29 and SW620 cells were seeded in $2 \mathrm{ml}$ supplemented DMEM per well into six-well culture plates to monitor cell growth and alterations in CD133 profile of sorted subpopulations. At defined time points, cells were enzymatically dissociated and cell numbers of three individual samples per condition were determined as described in routine culturing. Single-cell suspensions were analyzed for their CD133 cell surface expression via flow cytometry (see above). To obtain sufficient cell numbers for the analysis of CD133 expression at day 4 in 2-D culture, $6.5 \times 10^{4}$ sorted cells of each subpopulation in $13 \mathrm{ml}$ DMEM were inoculated in $10 \mathrm{~cm}$ culture dishes and were handled according to the six-well plate approach.

\section{3-D Assays of FACSorted Subpopulations}

3-D spheroid formation capacity of HT29 subpopulations after FACS was determined in liquid overlay using a standardized setup and culture conditions, ${ }^{25}$ as well as a limiting dilution approach. In the standardized procedure 1500 $\mathrm{CD}_{133^{+}}, \mathrm{CD} 133^{- \text {llow }}$ and mixed HT29 cells in $200 \mu \mathrm{l}$ medium were seeded per well into $1.5 \%$ agarose-coated 96 well plates. Spheroid formation, spheroid integrity and volume growth kinetics were monitored by semi-automated measurement of diameters and volumes from phase-contrast images as described earlier. ${ }^{25} \mathrm{~A}$ minimum of 18 spheroids per seeded population were analyzed. To study the CD133 profile of HT29 subpopulations throughout 3-D growth, 12-48 spheroids per condition were collected, enzymatically dissociated using a $0.1 \%$ trypsin $/ 0.04 \%$ EDTA solution and cell numbers were evaluated with the Casyl system. Resulting single-cell suspensions were processed for flow cytometric analysis as described above. The CD133 distribution at day 4 in culture (initiation period) was analyzed in duplicate whereas triplicates could be measured at later time points during 3-D culturing. 
In limiting dilution experiments, cell concentrations of FACSorted HT29 subpopulations were reduced in consecutive 1:10 dilution steps to provide cell suspensions with an average concentration of 5 and 25 cells $/ \mathrm{ml}$ standard medium. $200 \mu \mathrm{l}$ of these suspensions were then pipetted into each well of an agarose-coated 96-well plate; 48-60 wells were prepared for each suspension and three independent experiments were performed. Wells were microscopically imaged every 2-4 days and the development of sphere colonies with a size of $\geq 100 \mu \mathrm{m}$ was monitored over a period of 4 weeks. Spheroid formation capacity (\%) was calculated as the number of wells with single-sphere colonies divided by the number of wells seeded.

\section{Xenograft Formation Assay}

HT29, HCT-116 and SW620 cells were sorted according to their CD133 expression profile, subpopulations were reanalyzed for purity and viable cells were counted. Cell suspensions between 10 and $2.5 \times 10^{3}$ were prepared in $100 \mu \mathrm{l}$ of a 50\% Matrigel (BD Biosciences) in PBS solution and immediately injected subcutaneously into the hind limb of 8- to 10-week-old female NMRI (nu/nu) mice (Experimental Center, Medical Faculty, University of Technology Dresden). The injection of low cell numbers was performed as block experiments, each with a total of four animals and injections per cell number (100 and 10) and subpopulation, respectively. A total of four blocks with cells derived from independent preparations and sort procedures were averaged. SW480 cells were implanted without separation using 10000 or 500 cells per injection site to determine tumor formation rates. Palpable tumors were measured twice a week using a manual caliper to determine longest and perpendicular tumor axes and calculate tumor volumes by the formula of a rotational ellipsoid: $v=\pi / 6 \times a \times b^{2}$. Animals were killed when tumors reached a mean diameter of $1.2-1.5 \mathrm{~cm}$, upon completion of the observation period of 120 days after injection or when animals appeared to suffer. Animal facilities and all experiments were approved in accordance to institutional guidelines and German animal welfare regulations. Animals were fed with commercial laboratory animal diet and water ad libitum.

For the analysis of CD133 distribution, selected xenograft tumors were dissected at defined diameters, non-tumor tissue was removed and tumor material was then weighted and minced with scalpels. Tumor pieces were incubated in enzyme dissociation solution containing Collagenase NB 4G (Serva, Germany) with or without Hyaluronidase, DNAse (both Sigma, Germany) and trypsin/EDTA (PAN Biotech) overnight. The obtained cell suspensions were filtered through a $70-\mu \mathrm{m}$ mesh and cell numbers were determined. Aliquots were stained for flow cytometric analysis as described.

\section{Evaluation of Drug and Radiation Response}

Drug and radiation response of cell subpopulations were studied in classical 2-D CFA. In principle, HT29 cells were seeded and cultured as described in 2-D assays and HCT-116 cells were processed as depicted earlier. ${ }^{21}$ For drug treatment, however, cells (400 HT29 or 500 HCT-116) were inoculated in only $1 \mathrm{ml}$ culture medium per well and allowed to adhere over a period of $4 \mathrm{~h}$ under standard conditions before $1 \mathrm{ml}$ of conditioned DMEM containing double concentrated chemotherapeutics (Sigma-Aldrich, Germany) was added resulting in final concentrations of $0.1-25 \mu \mathrm{M}$ for 5-Fluorouracil and $1-50 \mu \mathrm{M}$ for Oxaliplatin. After an incubation time of $72 \mathrm{~h}$, drugs were removed by $100 \%$ medium exchange and cultures were kept in the incubator for the time indicated and processed as detailed previously. Cell survival curves were documented and $\mathrm{IC}_{50}$ values were determined for each experiment using a Hill-Fit with variable slope in the software GraphPadPrism (La Jolla, CA, USA). Experiments were performed at least in triplicate and the $\mathrm{IC}_{50}$ values from the individual Hill fits for each sorted subpopulation were averaged.

To evaluate radioresponse, cell subpopulations were seeded in CFA, allowed to adhere for $4 \mathrm{~h}$ and then irradiated at RT with single doses of $0.5-12 \mathrm{~Gy}(1.3 \mathrm{~Gy} / \mathrm{min}, 200 \mathrm{kV}$ X-rays; $0.5 \mathrm{~mm} \mathrm{Cu}$ filter; YxlonY.TU 320; Yxlon International, Germany). Colony formation capacity was analyzed as described and surviving fractions at $2 \mathrm{~Gy}\left(\mathrm{SF}_{2 \mathrm{~Gy}}\right)$ were calculated and averaged from dose-response curves of three individual experiments. A paired, two sided $t$-test was used to assess statistical significance.

\section{RESULTS}

In a previous study, we documented that $\mathrm{CD}_{13} 3^{+}$and CD133- ${ }^{-}$HCT-116 cells do not differ in any of the parameters of interest, including in vitro radioresponse and subcutaneous tumor formation, when injecting $\geq 2500$ cells per mouse. ${ }^{21}$ Because all of the animals developed a tumor, verification of our observation was required using a limiting dilution approach with 500, 100 and 10 cells per injection. As summarized in Table 1a, HCT-116 cells are highly potent and tumor take rate is still $100 \%$ at 100 cells injected per animal. A reduction in tumor formation was seen at 10 cells per animal. However, there was no significant difference in the tumor formation capacity of $\mathrm{CD} 133^{+}$vs CD133- ${ }^{-}$HCT-116. To also upgrade our previous data on therapy response, sensitivity of the respective HCT-116 subpopulations to 5-FU and Oxaliplatin, which are frequently implemented in clinical treatment regimes for advanced CRC, was analyzed. Dose-response curves ( $n=3$ for each drug) from 2-D CFAs revealed that $\mathrm{CD}_{133^{+}}$vs $\mathrm{CD} 133^{-}$HCT-116 subpopulations do not differ in drug sensitivity (Supplementary Figure 1). The mean $\mathrm{IC}_{50}$ values $( \pm$ s.d.) calculated from the individual dose-response curves are listed in Table 2a. These data confirm that HCT-116 cells do not show a therapy-relevant CD133-related phenotype.

The MSS/CIN cell line HT29 has been described to contain highly variable $\mathrm{CD}_{133^{+}}$fractions in different laboratories ranging from a few to $>95 \% .^{18,22,26-30}$ Because the fluorescence-staining procedure critically impacts the 
Table 1 Xenograft formation of (a) HCT-116, (b) HT29 and (c) SW620 colorectal cancer cell subpopulations sorted according to their CD133 expression and injected subcutaneously with matrigel into the hind limb of NMRI (nu/nu) mice

\begin{tabular}{llll}
$\begin{array}{l}\text { Number of } \\
\text { cells/s.c. injection }\end{array}$ & $\mathrm{CD}_{133^{+}}$ & $\mathrm{CD}_{133^{-/ \text {low }}}$ & $\begin{array}{c}\text { Original } \\
\text { (run-through sorter) }\end{array}$ \\
\hline
\end{tabular}

(a) HCT-116

$\begin{array}{lccc}500 & 5 / 5 & 5 / 5 & N D \\ 100 & 13 / 13 & 13 / 13 & 13 / 13 \\ 10 & 11 / 16 & 10 / 15 & 14 / 16\end{array}$

(b) HT29

$\begin{array}{lccc}2500 & 5 / 5 & 5 / 5 & 5 / 5 \\ 500 & 5 / 5 & 5 / 5 & 5 / 5 \\ 100 & 15 / 16 & 15 / 15 & 16 / 16 \\ 10 & 6 / 16 & 5 / 16 & 6 / 16\end{array}$

(c) SW620

\begin{tabular}{lccc}
100 & $8 / 8$ & $8 / 8$ & $4 / 4$ \\
10 & $13 / 16$ & $11 / 15$ & $12 / 13$ \\
\hline
\end{tabular}

Abbreviation: ND, not determined.

identification and quantification of $\mathrm{CD}_{133^{+}}$and $\mathrm{CD} 133^{-}$ cell fractions, we applied the same advanced staining protocol as for HCT-116 cells. The influence of signal amplification on flow cytometric discrimination of $\mathrm{CD} 133^{- \text {low }}$ vs $\mathrm{CD} 133^{+}$in HT29 cells is documented in Figure 1a. With two signal amplification steps, only a small HT29 subfraction remained in the isotype gate $\left(\mathrm{CD} 133^{- \text {llow }}\right)$, whereas $90.9 \pm 6.4 \%$ of exponentially growing HT29 cells in serum-containing DMEM clearly expressed CD133 on the cell surface. The resulting sort layout and a representative reanalysis after separation of the subpopulations are shown in Figure $1 \mathrm{~b}$. $\mathrm{CD}_{133^{+}}$and $\mathrm{CD} 133^{- \text {llow }}$ separated subpopulations did not overlap in fluorescence signal intensity. Subpopulations were studied in vitro and in vivo compared with originally distributed HT29 cells, which had undergone the same staining and sorting procedure (original run-through sorter).

$\mathrm{CD}_{133^{-/ l o w}}$ vs $\mathrm{CD} 133^{+} \mathrm{HT} 29$ cells were first analyzed in 2-D culture using colony formation and growth assays. The staining and sorting procedure in general reduced the plating efficiency (data not shown). However, independent of this, we observed a significant $(P<0.005)$ difference in colony formation capacity of the two subpopulations (Figure 2a). The plating efficiency of CD133 ${ }^{+}$HT29 cells was always higher than in their $\mathrm{CD} 133^{- \text {low }}$ counterparts $(29.9 \pm 4.9 \%$ vs $17.0 \pm 4.8 \%)$; the originally distributed control was intermediate $(26.6 \pm 5.7 \% ; n=6$ individual experiments). Despite the difference in colony formation, there was no growth advantage of the $\mathrm{CD}_{133^{+}}$HT29 cells; doubling times of the sorted HT29 cells were $23.3 \pm 2.2 \mathrm{~h}\left(\mathrm{CD} 133^{- \text {low }}\right)$,
Table 2 IC $_{50}$ values ( \pm s.d.) for (a) HCT-116 and (b) HT29 cell subpopulations sorted according to their CD133 expression profile, seeded in colony-forming assays and treated after attachment with different concentrations of either 5-FU or Oxaliplatin

\begin{tabular}{lcl}
\hline Treatment & $\mathrm{CD}_{133^{+}} \mathrm{CD} 133^{-/ \text {low }}$ & $\begin{array}{c}\text { Original } \\
\text { (run-through sorter) }\end{array}$
\end{tabular}

$\begin{array}{llll}\text { (a) } H C T-116-1 C_{50}(\mu M) & & & \\ \text { 5-Fluorouracil } & 5.7 \pm 1.2 & 6.3 \pm 1.6 & 6.4 \pm 1.6 \\ \text { Oxaliplatin } & 4.5 \pm 1.2 & 5.7 \pm 1.8 & 4.3 \pm 0.9\end{array}$

$\begin{array}{llll}\text { (b) } H \text { T29-IC } 50(\mu M) & & \\ \text { 5-Fluorouracil } & 5.4 \pm 1.6 & 4.6 \pm 2.5 & 4.9 \pm 2.2 \\ \text { Oxaliplatin } & 5.9 \pm 1.3 & 5.5 \pm 1.7 & 5.9 \pm 1.7 \\ & & & \\ & & & \\ \text { HT29-SF } 2 \text { SGy } & & & \\ \quad \text { Single-dose irradiation } & 64.1 \pm 5.1 & 67.1 \pm 5.2 & 65.4 \pm 8.7\end{array}$

A minimum of three independent cell survival curves per treatment were recorded and the $\mathrm{IC}_{50}$ values from the individual Hill fits for each subpopulation were averaged. HT29 subpopulations were also irradiated in colonyforming assays using single doses of 0-10 Gy and $\mathrm{SF}_{2 \mathrm{~Gy}}$ values ( \pm s.d.) were calculated and averaged as described in Materials and Methods.

$23.7 \pm 1.7 \mathrm{~h}\left(\mathrm{CD} 133^{+}\right)$and $24 \pm 2.5 \mathrm{~h}$ (originally distributed population; $n=3$; Figure $2 \mathrm{~b}$ ).

Because 3-D cultures better reflect in vivo micromilieu conditions than monolayer cultures, we also studied the growth behavior of HT29 subpopulations in a spheroid formation and growth assay. When $1500 \mathrm{CD} 133^{- \text {llow }}, \mathrm{CD} 133^{+}$ and originally distributed HT29 cells were seeded per well into agarose-coated 96-well plates, spheroids were formed in all wells in liquid overlay but the size of the spheroids after a defined initiation period differed significantly (Figure $2 \mathrm{c}$ ). At day 4 in culture, spheroids derived from CD133 ${ }^{+}$HT29 were significantly larger than those formed from the CD133-/low fraction $(298.1 \pm 38.3 \mathrm{~mm}$ vs $227.9 \pm 21.3 \mu \mathrm{m}$ in diameter; $P<0.005 ; n=5)$. The size of spheroids after inoculation of originally distributed control HT29 was intermediate $(274.5 \pm 42.7 \mu \mathrm{m})$, hence reflecting the contribution of the different fractions of $\sim 90 \% \mathrm{CD}_{13} 3^{+}$and $10 \% \mathrm{CD} 133^{- \text {llow }}$ cells. Despite this difference in initial spheroid diameter, spheroid volume growth kinetics were similar (Figure 2d, $n=5$ ), indicating that the discrepancy in spheroid size at day 4 does not result from a different proliferative activity but rather from the difference in clonogenic cell survival. We therefore evaluated the spheroid formation capacity of $\mathrm{CD}_{133^{+}}$vs $\mathrm{CD} 133^{- \text {llow }}$ HT29 cells in a limiting dilution approach by seeding mean cell numbers between 1 and 1500 and monitoring the formation of growing spheroids over a period of several weeks. There was no difference in spheroid formation rate of the different HT29 subpopulations if cell numbers of 5 and higher were seeded per well. With an average number of 5 cells/well, spheroid formation was 

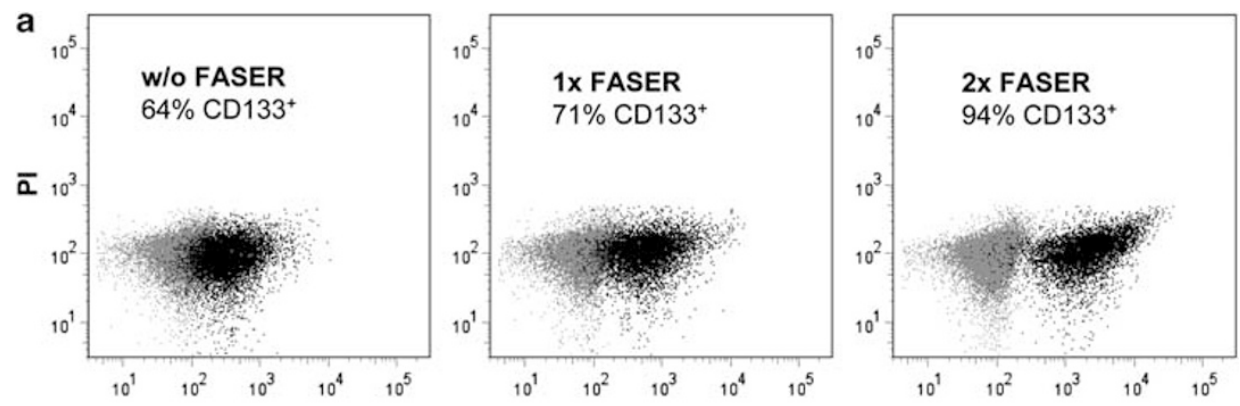

CD133-PE
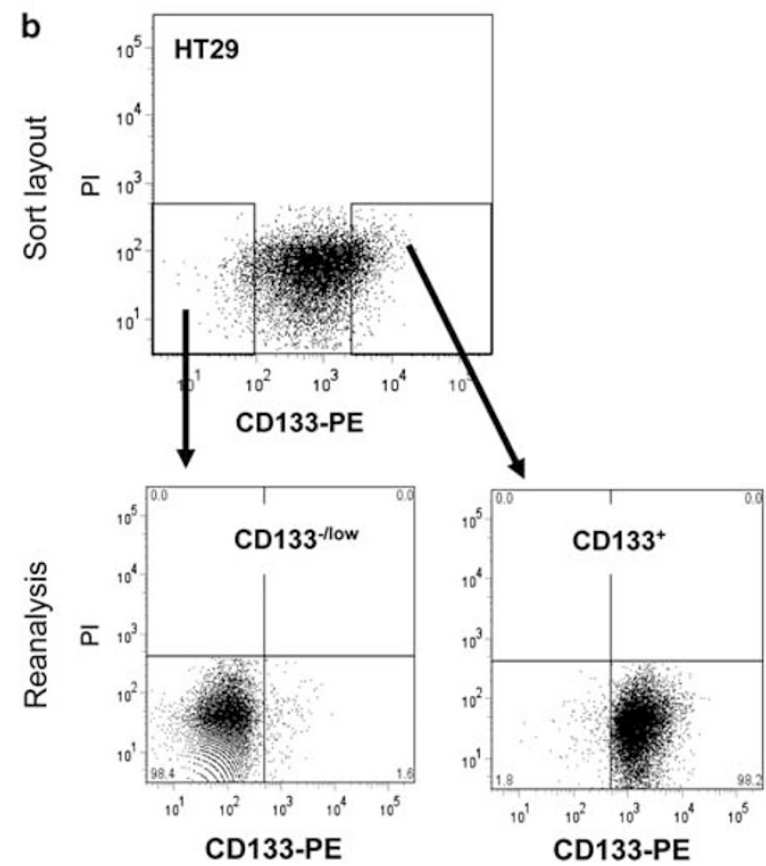

Figure 1 The experimental setup to separate $\mathrm{CD} 133^{-/ \text {low }}$ and $\mathrm{CD}_{133^{+}} \mathrm{HT} 29$ cell subpopulations includes signal amplification, which critically affects the quality and quantity of CD133 detection by flow cytometry. (a) Impact of Fluorescence Amplification by Sequential Employment of Reagents (FASER) on quantification and discrimination of HT29 subpopulations by flow cytometry after staining with an anti-CD133/1-PE antibody. Dot blot diagrams show HT29 cells stained without (left), with one (central) and with two rounds of fluorescence signal amplification (right). Only a small subset of $\sim 6 \%$ of the cells remains in the $\mathrm{CD} 133^{- \text {llow }}$ gate after two rounds of signal amplification and relative to the respective isotype control (grey), which underwent the same procedure. Propidium iodide (PI)-positive, membrane-defect cells and doublets were excluded. (b) The sort layout for

fluorescence-activated cell sorting (FACS) was established according to the CD133 expression level of HT29 cells after staining of single-cell suspensions with $2 \times$ FASER amplification. Sorted subpopulations were routinely reanalyzed as shown in the right panel for one representative experiment. The subfractions could be clearly identified; the purity according to the reanalysis gates was always $\geq 97 \%$ for both fractions.

achieved in $79.3 \pm 1.5 \%, 77.3 \pm 7.4 \%$ and $77.6 \pm 9.2 \%$ of the wells inoculated with $\mathrm{CD} 133^{+}, \mathrm{CD} 133^{- \text {llow }}$ and original HT29 cells, respectively. In contrast, spheroid formation rate clearly differed if cell suspensions were seeded to average 1 cell/well. Here, $\mathrm{CD} 133^{+}$cells showed a significantly higher capacity to form spheroids than the CD133-/low HT29 fraction with $37.5 \pm 6.0$ vs $25.5 \pm 7.8 \%$ of the wells containing growing spheroids $(P<0.05)$. The original run-through sorter $1 \mathrm{cell} /$ well control led to the formation of spheroids in $34.1 \pm 12.3 \%$ of the wells.

The CSC concept assumes that cells with the particular phenotype are more resistant to anticancer treatment and are responsible for recurrence of the disease. ${ }^{5,31}$ Further CFAs were thus performed to evaluate the susceptibility of HT29 subpopulations against 5-FU, Oxaliplatin and single-dose irradiation. According to HCT-116 cells, CD133 ${ }^{+}$and CD133-/low HT29 cell populations did neither significantly differ in drug response nor in radiosensitivity (Table $2 \mathrm{~b}$ and Supplementary Figure 2). Because 2-D colony and spheroid formation capacity after single-cell seeding of $\mathrm{CD} 133^{+} \mathrm{HT} 29$ cells was higher than for their CD133-/low counterparts, and on the basis of literature data, we hypothesized a different tumor formation capacity of the subpopulations. Subcutaneous injection of 2500 and 500 cells $\left(\mathrm{CD} 133^{+}\right.$, 


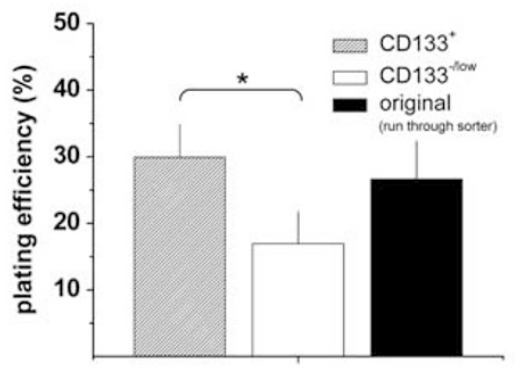

C

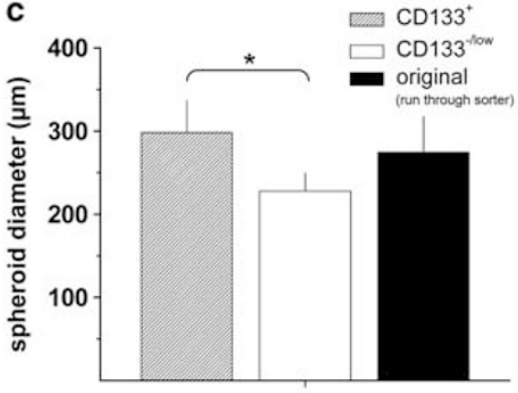

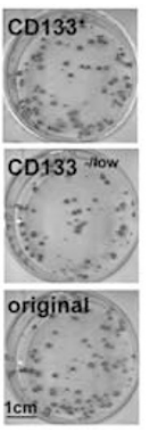

b


Figure $2 \mathrm{CD}_{133^{+}}$and $\mathrm{CD} 133^{- \text {llow }} \mathrm{HT} 29$ cells differ in colony formation capacity and initial spheroid size but exhibit comparable 2-D and 3-D growth kinetics. 2-D and 3-D growth characteristics were monitored for FACSorted CD133 ${ }^{+}$vs CD133-/low $\mathrm{HT29}$ cells in comparison to original/mixed HT29 cells that underwent the same experimental procedure (original run-through sorter). (a) Plating efficiencies ( + s.d.) of HT29 subpopulations averaged from $n=6$ independent experiments. CD133 ${ }^{+}$HT29 cells show a higher colony-forming capacity than their CD133 ${ }^{-/ \text {low }}$ counterparts. Representative wells with colonies derived from each subpopulation $\left(\mathrm{CD}_{133^{+}}, \mathrm{CD} 133^{- \text {llow }}\right.$, original) are shown in the right panel. (b) Cell numbers for the $\mathrm{CD}_{133^{-}}$/low seeded fraction remain lower throughout culturing as compared with the $\mathrm{CD} 133^{+}$and the original populations, but growth kinetics and doubling times are comparable. A representative monolayer growth experiment from $n=3$ is shown; three samples were analyzed for each time point per experimental series. (c) Spheroids derived from $1500 \mathrm{CD} 133^{+} \mathrm{HT} 29$ cells are significantly larger at day 4 in liquid overlay culture than those originated from the same number of CD133-/low HT29 cells. Spheroids were monitored by phase-contrast imaging and spheroid diameters were analyzed and averaged for $\geq 16$ spheroids per experimental series. The graph shows mean spheroid sizes ( + s.d.) from $n=4$ independent experiments. (d) Spheroid volume growth recorded after seeding of $\mathrm{CD}_{13} 3^{+}, \mathrm{CD} 133^{- \text {llow }}$ and original HT29 subpopulations according to (c) does not show a difference in 3-D growth kinetics. A representative experiment from $n=4$ independent series is shown.

CD133-/low and original run-through sorter) into NMRI (nu/nu) mice using a matrigel/PBS mixture resulted in $100 \%$ tumor formation. We then performed block experiments with four independent staining, sorting and dilution series to inject 100 and 10 cells per mouse (four mice per block for each population). In the 100 cell cohorts, only one injection failed to produce a tumor. By contrast, the injection of only 10 cells resulted in a clearly reduced tumor take. However, no difference in tumor formation rate was observed for the different HT29 subpopulations sorted according to their flow cytometric CD133 expression profile (Table 1b).

Significant phenotypic differences of $\mathrm{CD}_{133^{+}}$and CD133-/low HT29 cell subpopulations in vitro were observed but were not as pronounced as expected and did not correlate with in vivo tumor formation. We therefore studied colony formation under tissue normoxia ( $4 \%$ oxygen) to more closely reflect the oxygen conditions upon subcutaneous injection of the cells and found HT29 clonogenic cell survival after sorting in general to be enhanced in tissue normoxic $v s$ culture normoxic, tissue hyperoxic conditions (4 vs 21\% $\mathrm{O}_{2}$ ). The benefit was significantly higher for the $\mathrm{CD} 133^{-/ \text {low }}$
HT29 fraction, partly but not entirely compensating for the difference in clonogenic survival of $\mathrm{CD}_{133^{+}}$vs $\mathrm{CD} 133^{- \text {llow }}$ HT29 cells plating (Supplementary Figure 3).

We further raised the question whether the particular CD133 phenotypes are conserved throughout extended 2-D and 3-D culturing as well as in vivo. The distribution of $\mathrm{CD}_{133^{+}}$and $\mathrm{CD} 133^{-/ \text {low }}$ fractions was thus investigated in more detail by flow cytometry in cells cultured for various times after FACSorting. There was no significant change in the $\mathrm{CD}_{133}{ }^{+}$sorted fraction throughout 2-D culturing; this cell population remained positive for CD133. However, already at day nine in $2-\mathrm{D}$ cultures, $81.1 \pm 3.5 \%$ of the cells derived from the CD133-/low HT29 population had to be classified as $\mathrm{CD}_{133^{+}}(n=3)$. Ten days later (day 19 after FACS), the population had readjusted to the original distribution with only $4.8 \pm 2.2 \%$ HT29 cells appearing in the CD $133^{- \text {low }}$, isotype gate (Figure $3 \mathrm{a}$ ). To prove that the unexpected redistribution of the CD133-/low -sorted cells in culture was not due to contamination by minor fractions of $\mathrm{CD} 33^{+}$HT29 cells, we also analyzed single-cell suspensions from two individual sorts already at day 4 after sorting and 

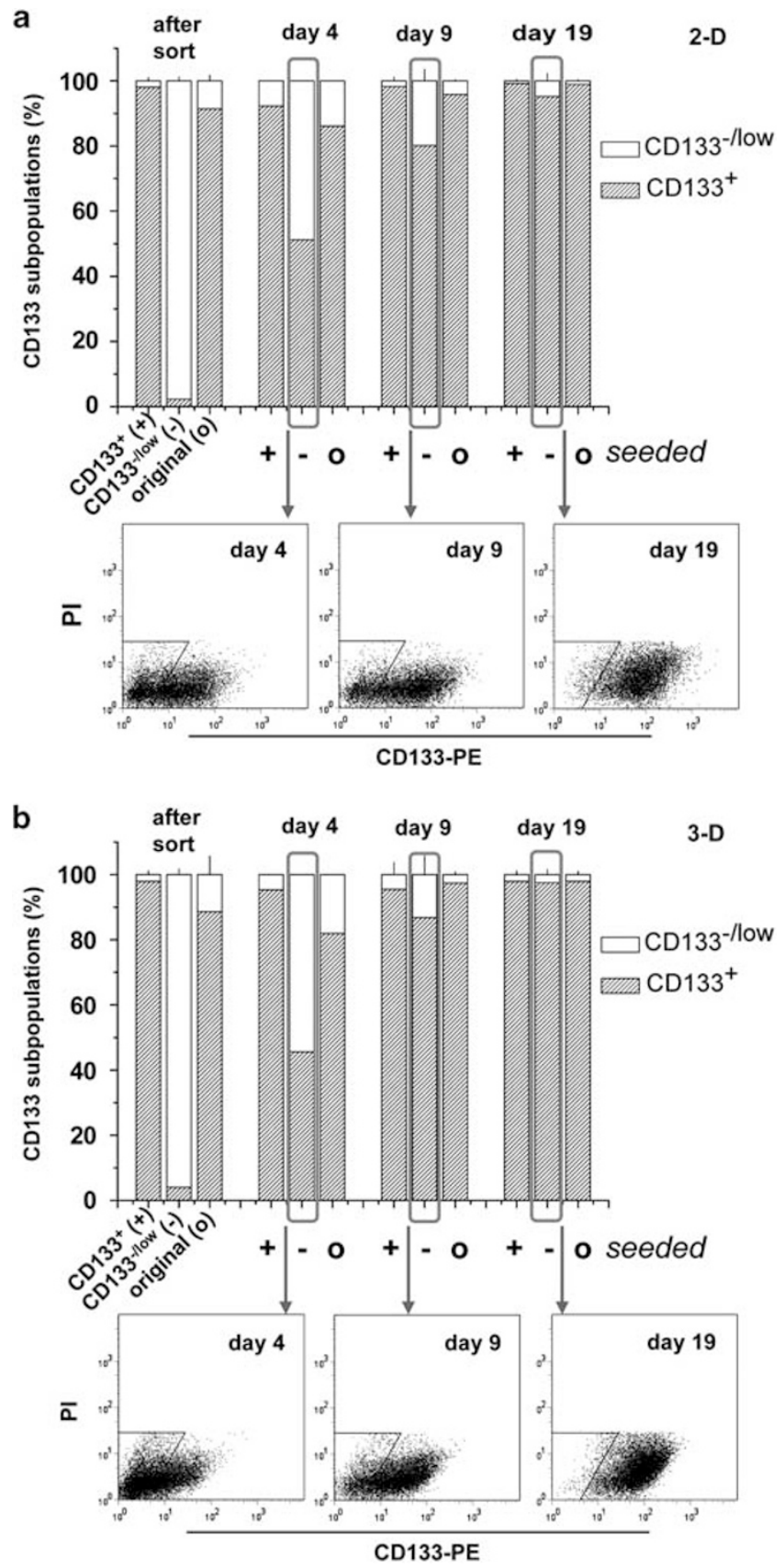

Figure 3 CD133 distribution after seeding of CD133-/low FACSorted HT29 cells is readjusted during short-term 2-D and 3-D culturing. The distribution of CD133 fractions was monitored in 2-D (a) and 3-D (b) culture at days 4, 9 and 19 after FACSorting of the respective CD133 ${ }^{+}$ and $\mathrm{CD} 133^{- \text {llow }}$ subpopulations. Original HT29 cells (o) as well as $\mathrm{CD}_{133^{+}}(+)$and $\mathrm{CD} 133^{- \text {llow }}(-)$ subpopulations directly after sort are documented in the left set of columns. Most notably, cultures derived from the $\mathrm{CD} 133^{- \text {llow }}$ population contained a high percentage of $\mathrm{CD}_{133^{+}}$cells already 4 days after FACSorting and reached $>90 \%$ at day 19 after sort both in 2-D and 3-D culture. Representative flow cytometric dot plot diagrams of the seeded CD133-/low subpopulation after 4, 9, and 19 days in culture are shown in the lower panels. Single-cell suspensions were prepared and stained according to Figure 1; Propidium iodide (PI)-positive, membrane-defect cells and doublets were excluded. found $48.4 \%$ and $55.7 \%$, respectively, of the cells derived from the $\mathrm{CD} 133^{- \text {llow }}$ subpopulation to express CD133 on the cell surface. The massive increase in the $\mathrm{CD} 133^{+}$fraction over a period of only 4 days, ie with a maximum of four possible culture doublings in 2-D culture (doubling time $\sim 22-24 \mathrm{~h}$ as documented earlier), proved that CD133-/low cells re-express CD133 on their surface. Similar changes were recorded in 3-D culture (Figure 3b). In two independent experiments, we found only $47.8 \%$ and $61 \%$, respectively, of the cells to have maintained a $\mathrm{CD} 133^{-/ \text {low }}$ phenotype in 4day-old spheroids derived from the FACSorted CD133-/low HT29 population. The proportion of CD133-/low cells further decreased to reach $13.2 \pm 5.6 \%$ and $2.5 \pm 1.5 \%$ at days 9 and 19 after seeding $(n=3)$ leading to the assumption that CD133 is rapidly re-expressed in both 2-D and 3-D culture. Six xenograft tumors with a diameter of $1.0-1.2 \mathrm{~cm}$ originated from $1 \times 10^{4} \mathrm{CD} 133^{- \text {low }}$ HT29 cells were extracted (day 30-40 after s.c. injection), dissociated and analyzed by flow cytometry to substantiate a potential redistribution in vivo. Indeed, the majority of the human cells in suspensions derived from 6/6 xenografts were positive for CD133. Three examples are shown in Figure $4 \mathrm{~b}$.

A similarly rapid and massive change in CD133 expression profile throughout in vitro growth and also in in vivo xenografts was not seen in the HCT-116 $\mathrm{CD} 133^{-}$fraction. ${ }^{21,32}$ We therefore reassessed the findings in HT29 cell cultures. Flow cytometric analyses directly after separation of CD133 ${ }^{+}$ and CD133-llow HT29 cells always showed two clearly distinct populations with negligible signal overlap (Figure 1b). However, we frequently observed a striking right shift of the fluorescence signal of the entire $\mathrm{CD} 133^{- \text {llow }}$ population relative to the respective sorting gate, which may not exclusively be attributed to methodological constraints. Western blot analyses revealed a clear enrichment of the respective $\mathrm{CD}_{133^{-}}$/low and $\mathrm{CD}_{133^{+}}$HT29 populations upon sorting. However, an extremely faint CD133 signal was reproducibly seen in whole cell protein extracts from the CD133-/low -sorted HT29 subpopulation using two different antibodies directed either against the extracellular CD133 epitope AC133 or an intracellular C-terminal region of the CD133 molecule (Figure 5a). At this time of analysis it was not possible to verify if the signal came from a minor contaminating $\mathrm{CD}_{133^{+}}$cell fraction or if the entire $\mathrm{CD} 133^{-/ \text {low }}$ HT29 population showed marginal CD133 expression. The contamination hypothesis, however, is unlikely in light of the rapid CD133 re-expression in the $\mathrm{CD} 133^{-/ \text {low }}$ HT29 cell population throughout culturing, which could also be verified in protein extracts from 2-D cultures at days 4 and 14 after FACSorting (Figure $5 b$ and $c$ ).

Based on this observation and the awareness of the discrepant binding (epitopes) of the different anti-CD133 antibodies, we reassessed the CD133 protein expression of several cell lines that were classified to contain $\mathrm{CD} 133^{+}$and CD133-/low fractions in flow cytometry. Exponentially grown SW1417 and LS1034 cells contain subfractions of 
a

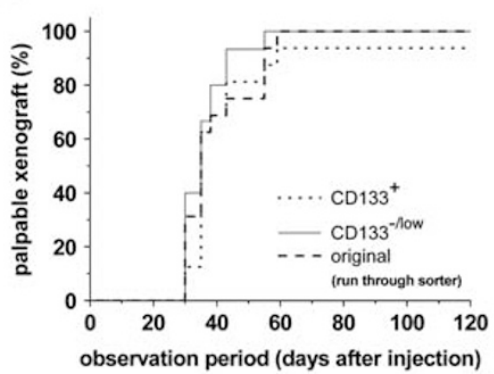

10 HT29 cells

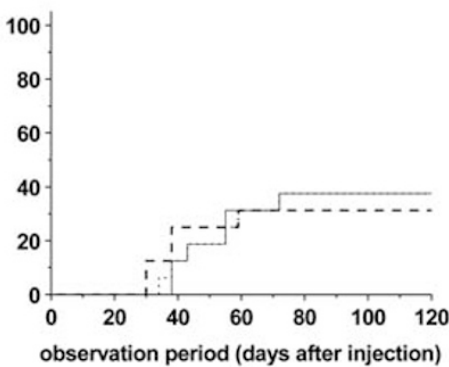

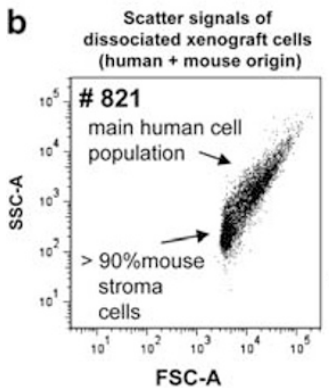
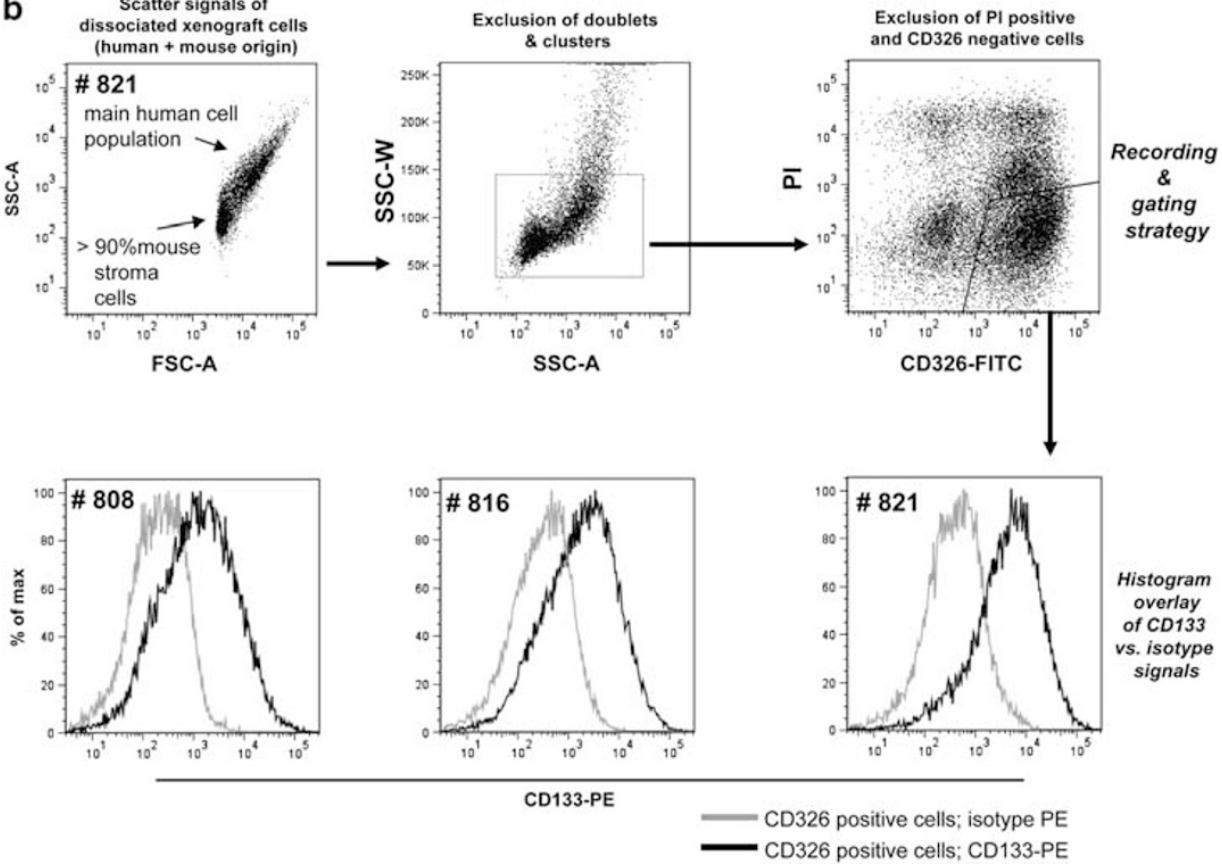

Histogram

overlay
of $C D 133$

vs. isotype

signals

CD133-PE

CD326 positive cells; isotype $\mathrm{PE}$
$\mathrm{CD} 326$ positive cells; $\mathrm{CD} 133-\mathrm{PE}$

Figure 4 Xenograft formation is not different or delayed in any of the CD133-related HT29 subpopulations and CD133 is re-expressed in xenograft tumors originated from CD133-/low FACSorted HT29 cells. (a) Proportion of palpable tumors as a function of time after injection of 100 or 10 CD133 ${ }^{+}$, CD133-/low and original mixed HT29 fractions. (b) Dot plot diagrams documenting the gating strategy including FCS-A vs SSC-A, SSC-A vs SSC-W and CD326 vs propidium iodide (PI) (upper panel from left to right) to identify single membrane intact, human cells in xenograft preparations for CD133 surface expression analysis. Three representative CD133 histogram overlays of dissociated xenograft tumors originated from $\mathrm{CD} 133^{-/ \text {low }}$ HT29 cells are shown (lower panel) to visualize the in vivo re-expression of CD133 relative to the respective isotype controls.

$69.7 \pm 9.1 \%$ and $38.5 \pm 10.9 \%$, respectively, with clear CD133 cell surface expression. Western blot analyses of whole cell protein extracts from the $\mathrm{CD} 133^{- \text {/low }}$-sorted fractions of these two cell lines, however, identified CD133 protein bands according to HT29 cells (Sort layout, representative western blots and quantification of relative signal intensities are given in Supplementary Figure 4A-D. We used one of these cell models, LS1034, to verify by flow cytometry if the $\mathrm{CD} 133^{- \text {llow }}$ population contains intracellular CD133 protein. For this purpose, we established a co-staining for two CD133-specific antibodies (AC133 and $\mathrm{W} 6 \mathrm{~B} 3 \mathrm{C} 1)$ in viable and fixed, permeabilized cells. As expected, the $\mathrm{CD} 133^{+}$ $\left(\mathrm{AC}_{133^{+}}\right)$population was also positive upon staining with the W6B3C1 (data not shown). The $\mathrm{CD} 133^{- \text {llow }}$ population, however, was found to be negative for $\mathrm{W} 6 \mathrm{~B} 3 \mathrm{C} 1$ only if cell membranes were intact, whereas cell permeabilization resulted in a clear positive CD133 protein signal in the majority of these cells (Supplementary Figure 4E). This reveals that CD133 cell surface presentation and intracellular protein can differ critically.

In contrast to the CD133-/low fractions in HT29, SW1417 and LS1034 cultures, CD133 protein in $\mathrm{CD}_{133^{-}}$-sorted SW620 cells was at or below detection level in western blot analyses (Figure 6b). SW620 cells were therefore chosen as an additional model to evaluate if $\mathrm{CD} 133^{+}$and $\mathrm{CD} 133^{-}$-sorted subpopulations from CRC cell lines differ in in vitro and in vivo behavior and to substantiate our finding that CD133 can be re-expressed on the surface of CD133-llow cell line populations. In exponential culture, $67.4 \pm 2.5 \%$ of the SW620 cells present CD133 on their surface; the subpopulations are clearly distinguishable (Figure 6a upper panel). Reanalysis of sorted subpopulations revealed high 

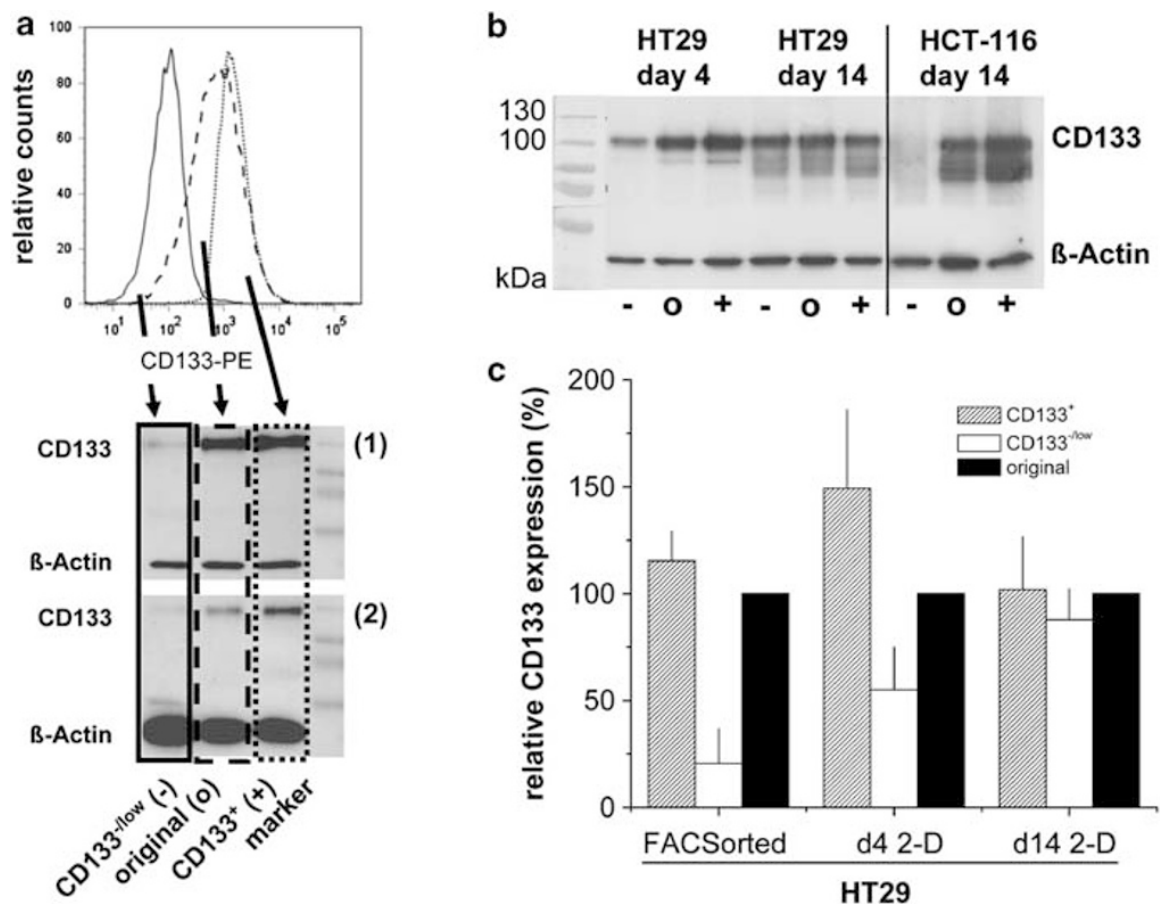

Figure 5 Western blot analyses reveal rapid re-expression of CD133 in CD133-/low -sorted HT29 but not HCT-116 fractions during short-term culture. (a) Histogram overlay (upper panel) of flow cytometric CD133 fluorescence signals from FACSorted HT29 subpopulations and originally distributed cell line and representative western blots (lower panel) of whole cell protein extracts from the subpopulations using antibodies (1) W6B3C1 (directed against an extracellular epitope) and (2) Ab19898 (directed against a C-terminal, intracellular epitope) for CD133 detection; a weak CD133 signal in the $\mathrm{CD} 133^{- \text {/low }}$ HT29 subpopulation is seen. (b) Representative western blots using Ab19898 to determine CD133 protein in CD133 ${ }^{+}, \mathrm{CD}_{133^{-/ \text {low }}}$ and originally distributed HT29 populations that were seeded and cultured for 4 and 14 days. The respective HCT-116 subpopulations after 14 days in $2-D$ culture were analyzed in parallel. (c) Densitometric analysis of $n=3$ independent western blots and protein extracts, respectively, for each HT29 subpopulation using antibody (2) Ab19898 is shown. Relative mean values ( + s.d.) are given with CD133 protein expression normalized to $\beta$-actin and originally distributed controls set to $100 \%$.

purities of $\geq 97 \%$. No significant difference was found in colony formation capacity of $\mathrm{CD}_{133^{-}}$vs $\mathrm{CD} 133^{+}$SW620 cells. Similar to the results with HT29, CD133- SW620 cells rapidly re-expressed CD133 protein on their surface in 2-D culture as documented in Figure 6d. The proportion of CD133-expressing cells increased from $9.3 \pm 4.3 \%$ at day 4 to $55.6 \pm 7.5 \%$ and $63.8 \pm 0.9 \%$ at days 9 and 18 , respectively. In addition, in vivo tumor formation capacity of $\mathrm{CD} 133^{+}$and CD133- SW620 populations did not differ (Table 1c) and also no subpopulation-dependent delay in tumor formation was observed (Figure 7a). Roughly all $(95.4 \pm 4.0 \%$ in $n=10$ xenografts) of the CD326-positive human cells from dissociated SW620 xenografts originated from the CD133SW620 population re-expressed CD133 in vivo (examples are documented in Figure 7b). Hence, CD133 re-expression in the SW620 in vivo model was even more pronounced than in HT29 xenografts.

Finally, we analyzed the CD133 expression pattern of dissociated xenograft tumors developed after the injection of SW480 colorectal cancer cells, which were negative for CD133 cell surface expression in vitro in 2-D culture and also showed a lower tumor formation rate in NMRI $(\mathrm{nu} / \mathrm{nu})$ mice than the SW620 cell line, which were derived from a lymph node metastasis of the same patient. Figure $7 \mathrm{c}$ documents the CD133 profile of three different xenografts showing a clear positive shift in the CD133 fluorescence and an increase in the fraction with a signal intensity above isotype. Taken together the re-expression or upregulation of CD133 in vivo appears to be a common phenomenon in $\mathrm{CD}_{133^{-/ l o w}}$ MSS CRC cell lines and subpopulations.

\section{DISCUSSION}

Numerous studies indicate that the CD133-expressing fraction is a relevant prognostic factor for disease-free and overall survival $^{33-41}$ and also relates to response to treatment. ${ }^{33,39,41-45}$ However, there has been an ongoing discussion on the usefulness of $\mathrm{CD} 133$ on the one hand and established CRC cell lines on the other hand as tools in cancer stem cell research and treatment. Indeed, the functional and causal relation between CD133 protein expression and putative cancer stemness and plasticity is still a matter of debate. ${ }^{6,10,46-51}$ This prompted us to further investigate the relevance of CD133 expression in CRC cell lines, which are integral to many drug development test platforms.

The decision to examine HT29 cells reflecting the more common MSS pathway to colorectal carcinogenesis as 
a
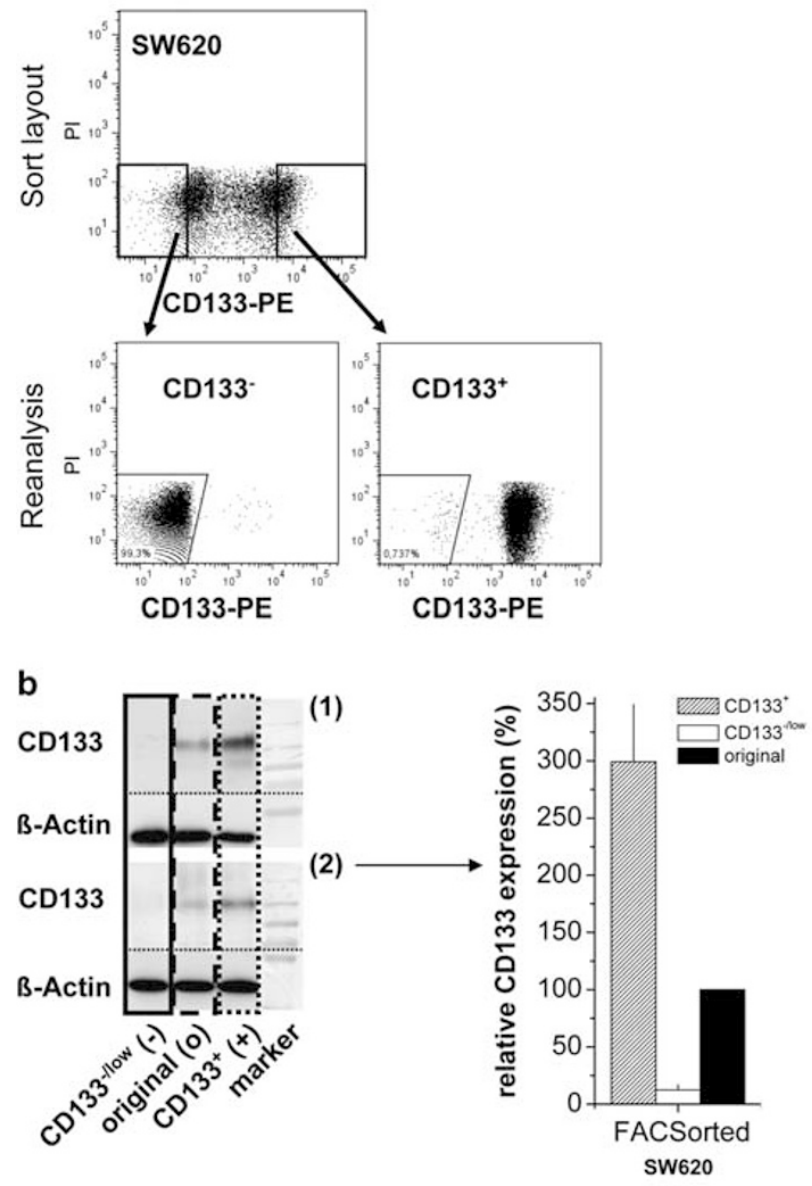

c
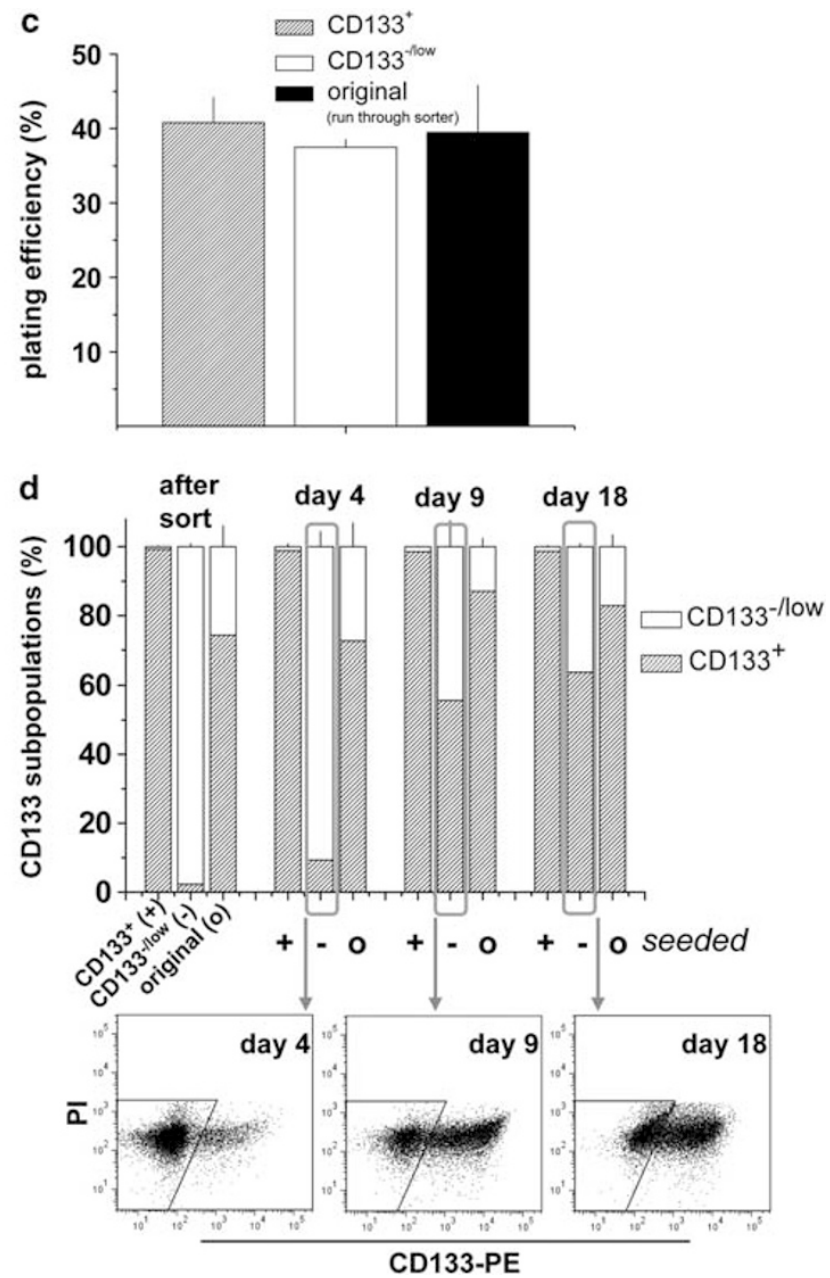

Figure 6 Reanalysis of FACSorted SW620 CD133 subpopulations by western blotting reveal that CD133 protein is under the detection level in CD133SW620 cells. Separated SW620 CD133+/CD133- subpopulations do not differ in colony formation capacity and rapid re-expression/upregulation of CD133 protein in the CD133- fraction was seen in 2-D culture. (a) Sort layout and representative reanalysis of SW620 cells, which exhibit clearly distinguishable subpopulations according to their CD133 expression. A purity $>98 \%$ was reached after FACS. (b) Western blot analyses using whole cell protein extracts from separated subpopulations and (1) W6B3C1 or (2) Ab19898 anti-CD133 Ab for detection. Representative western blots and densitometric analyses ( + s.d.) of (2) from $n=3$ independent experiments are shown. Analyses were performed according to Figure 5c. (c) Colony formation of $\mathrm{CD}_{133^{+}}, \mathrm{CD} 133^{-}$and original SW620 cells. (d) CD133+ $/ \mathrm{CD} 133^{-}$ratios in SW620 cells directly after sort and in descendant 2-D cultures. Representative dot plot diagrams visualizing CD133 re-expression on days 4, 9 and 18 are documented (lower panel); analytical strategy and quantification according to Figure 3.

opposed to the MSI cell line HCT-116 studied earlier ${ }^{21}$ was primarily driven by literature data indicating a difference in tumorigenic potential of $\mathrm{HT} 29 \mathrm{CD}_{133^{+}}$vs $\mathrm{CD} 133^{-}$ subfractions. ${ }^{22}$ In addition, a decrease in CD133 expression in HT29 populations with a higher grade of differentiation was reported, ${ }^{18}$ and $\mathrm{CD} 133$ expression was found to be enhanced in this cell line upon irradiation. ${ }^{43}$ Furthermore, CD133 knockdown was shown to result in greater susceptibility to staurosporine-induced apoptosis and reduced cell motility. ${ }^{29}$ Taken together, these findings suggested that $\mathrm{CD} 133$ has a role in response to treatment and/or CSC behavior of HT29 cells. A literature review, however, also indicated considerable differences in CD133 expression levels in HT29 cultures in various laboratories.
This may be attributed to (i) different growth and environmental conditions, (ii) selection of particular HT29 clones, or (iii) different staining protocols, detection technologies and analytical tools. ${ }^{18,22,26-30}$ Because CD133 expression was found to be elevated upon infection with Mycoplasma hyorhinis, ${ }^{28}$ our cell lines were routinely tested negative for mycoplasma and verified for genetic origin to exclude artificial modifications.

The 92-110 kDa glycoprotein CD133 (prominin-1) consists of an extracellular N-terminal domain with two large glycosylated extracellular loops, five transmembrane domains and a cytoplasmic C-terminus. ${ }^{52-55}$ The anti-CD133/1 (clone AC133) has most frequently been applied to isolate cells with different CD133 surface presentation and also 

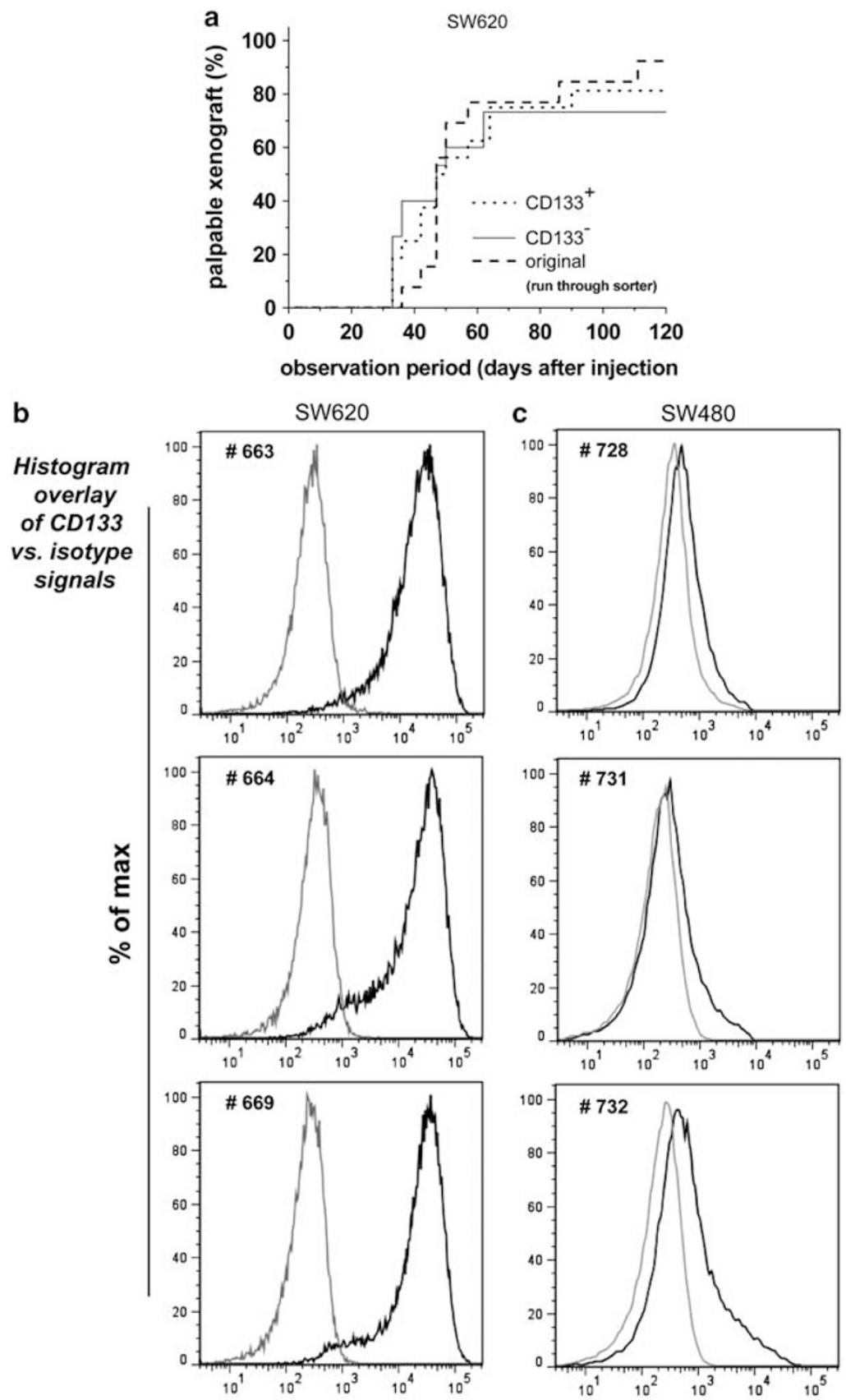

\section{CD133-PE $=$ CD326 positive cells; isotype $\mathrm{PE}$ CD326 positive cells; CD133-PE}

Figure 7 Xenograft formation is not different or delayed in any of the CD133-related SW620 subpopulations. CD133 is re-expressed in xenograft tumors originating from CD133-/low FACSorted SW620 cells and is also induced in xenografts of the CD133- cell line SW480. (a) Proportion of palpable tumors as a function of time after injection of $10 \mathrm{CD}_{133^{+}}, \mathrm{CD} 133^{- \text {/low }}$ and original mixed SW620 fractions. (b) Representative histogram overlays of three dissociated xenograft tumors originated from CD133- SW620 cells showing CD133 cell surface presentation relative to the respective isotype controls; analytical strategy as described in Figure 4b. (c) Histogram overlays according to (b) of three dissociated xenograft tumors originated from SW480 cells classified in vitro as CD133- cell line.

served as the tool in our study. ${ }^{21}$ The antibody was long thought to bind to an extracellular glycosylated epitope $e^{54,56}$ and false-positivity/negativity has been supposed to be due to the presence of alternatively spliced isoforms, truncated proteins or others. ${ }^{52}$ However, the hypothesis that AC133 recognizes a glycosylated epitope was questioned, ${ }^{27}$ and 
Kemper et $a l^{50}$ recently showed that it binds to a nonglycosylated epitope on the second extracellular loop at exons 16-24. Because of these controversial issues and because protein processing or masking of epitope by protein folding may be of relevance for antibody binding capacity, ${ }^{50,57}$ it is advisable, but not yet routine, to confirm flow cytometric data with independent protein detection methods and/or other anti-CD133 antibodies. We performed western blot analyses of whole cell protein extracts from subpopulations of interest using the AC133 as well as an alternative antibody clone, which binds to an intracellular C-terminal epitope to determine CD133 protein independent of its cellular location. In contrast to HCT-116, we frequently found a weak CD133 protein band in the CD133-negative-sorted HT29 cell subpopulation and also in the respective CD133- SW1417 and LS1034 cell fractions. This, together with the slight shift in the flow cytometric signal of the CD133-low -sorted HT29 population to higher mean fluorescence values, and the finding that CD133 cell surface presentation and intracellular protein can critically differ-as shown herein via flow cytometry using the LS1034 cell model-implies that $\mathrm{CD} 133^{- \text {llow }}$ cells may indeed express CD133 protein. The plasticity of $\mathrm{CD} 133^{- \text {low }} \mathrm{HT} 29$ cells with respect to $\mathrm{CD} 133$ protein expression is further confirmed by the rapid re-expression of CD133 on the surface of this subpopulation during continued tissue culture and may explain the transient phenotype of $\mathrm{CD} 133^{+}$ vs $\mathrm{CD} 133^{- \text {llow }}$ HT29 fractions and lack of difference in tumorigenic potential.

SW620 cells that exhibit clearly distinguishable CD133and $\mathrm{CD}_{13}{ }^{+}$subpopulations in vitro as verified in western blot analyses were included in our study because a CD133 ${ }^{+}$ SW620 subfraction was also reported earlier to result in faster tumor formation and larger xenografts after subcutaneous or orthotopic injection into NOD/SCID or nude mice. ${ }^{23,58}$ Our data, however, reveal, that $\mathrm{CD} 133^{-}$and $\mathrm{CD} 133^{+}$SW620 subpopulations neither differ in clonogenic survival in vitro nor in tumor formation capacity in NMRI (nu/nu) mice. And, the $\mathrm{CD}_{133^{-}}$population of this cell line also appeared to rapidly re-express $\mathrm{CD} 133$ protein for presentation on the cell surface, a modulation particularly induced after in vivo engraftment. Interestingly, even the CD133-negative cell line SW480 showed an increase in CD133 signal in xenograft tumors. From these data and because xenografts derived from $\mathrm{CD}_{133^{-}}{ }^{-}$HCT-116 cells also contained variable $\mathrm{CD}_{133^{+}}$fractions in spite of lack of rapid re-expression in vitro, we conclude that $\mathrm{CD} 133$ presentation in CRC cell lines is highly plastic independent of the underlying carcinogenesis pathway and common genetic alterations (see Table 3 and Supplementary Table 1). We did not find the CD133 in vitro profile of any of the cell lines under standard conditions to be associated with tumorpropagating potential but all cell lines and cell line populations studied were to some extent capable to (re-)express CD133 protein in vivo.
The reason(s) for the significant and reproducible difference for $\mathrm{CD}_{133^{+}}$vs $\mathrm{CD} 133^{-/ \text {low }}$ HT29 subpopulations with respect to colony and spheroid formation still remains elusive. In brain tumors, the distribution of CD133-positive vs negative subpopulations was found to be modulated by the oxygen level ${ }^{59-62}$ and hypoxic niches are discussed to support stemness phenotype in both normal tissues and solid cancers. ${ }^{63}$ In the present study, oxygen concentration is unlikely to cause rapid CD133 protein re-expression in HT29 2-D cultures. It may be speculated though, that such effects may further contribute to the reappearance of $\mathrm{CD}_{133^{+}}$populations in vivo and the lack of a nontumorigenic $\mathrm{CD} 133^{-}$phenotype because tissue normoxic conditions already partly neutralized the in vitro survival advantage of the $\mathrm{CD}_{133^{+}} \mathrm{HT} 29$ population. The impact of therapeutically relevant hypoxia and intermittent oxygen supply due to the chaotic, immature vascular network in solid tumors in the scenario of CD133 expression and plasticity is of particular interest in this context and subject to further systematic study.

Recently, a cell-density-related upregulation of CD133 expression in $\mathrm{CaCo} 2$ cells in vitro was described. ${ }^{64} \mathrm{We}$ observed similar changes in SW620 cells. When CD133sorted SW620 cells were passaged according to a standard protocol and kept in an exponential state over a culture period of 18 days, the proportion of $\mathrm{CD}_{133^{+}}$cells increased to $14-20 \%$, whereas without sub-culturing $63.8 \pm 0.9 \%$ of the cells became positive on their cell surface (Supplementary Figure 5). Such effect is likely to also contribute to the upregulation of CD133 in some xenografts but may be less relevant in others, eg $\mathrm{CD}_{133^{-}} \mathrm{HCT}^{-116}$ populations did not become positive with increasing density over a period of 2 weeks in culture. Interestingly, $95 \%$ of the FACSorted CD133 ${ }^{+}$SW620 cells maintained their positivity independent of passaging, which implies that CD133 expression is density-dependent only in a subfraction of the cell line.

Analogous studies have to verify, if other biomarkers discussed with CRC stemness phenotype such as CD44 (refs. 65,66) are also affected by such environmental constraints. The cell lines used herein clearly differ in their CD44 cell surface profile under identical conditions in exponential 2-D culture (Supplementary Figure 6) and some of them could be models of interest in this context.

Taken together, our data show that despite a potential phenotype in vitro, reduced or lack of CD133 presentation neither relate to loss of tumorigenic potential in the CRC cell lines studied herein nor does it correlate with a different response to treatment, most probably because the majority of the MSS cells is capable of re-expressing CD133 on the cell surface. These cell lines may in principle possess a cancer stem-like phenotype and the plasticity required to survive in a (patho)physiological in vivo environment. Because of their particularly high tumor take rate, they are poor models for scrutinizing the cancer stem cell hypothesis. However, they 
Table 3 Overview of data on cell line characteristics and behavior related to CD133 (AC133) cell surface expression

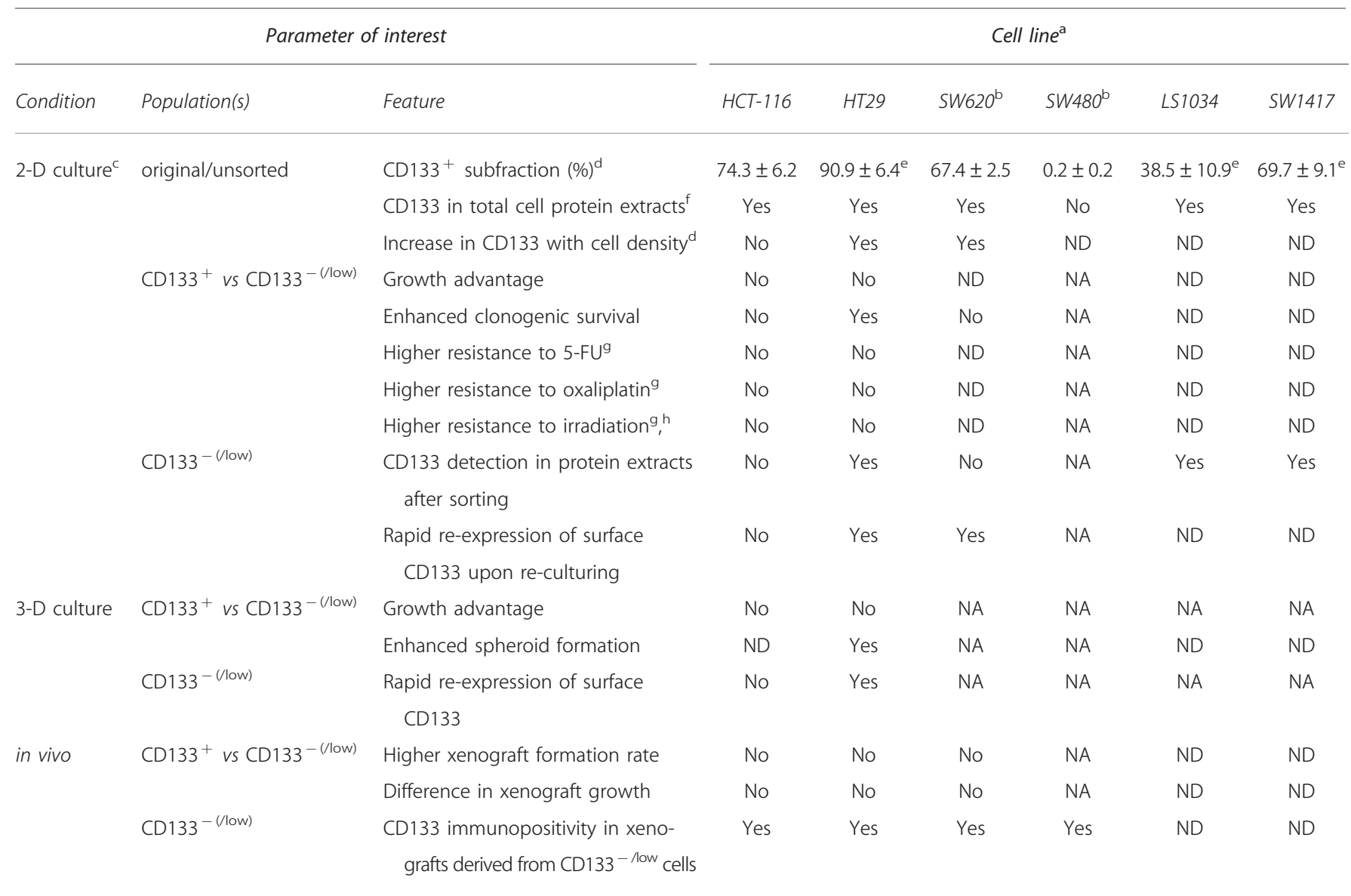

Abbreviations: NA, not applicable; ND, not determined.

${ }^{a}$ MSI/MSS status and selected information on oncogene/suppressor gene profiles are given in Supplementary Table 1; all cell lines cultured under identical conditions.

${ }^{\mathrm{b}}$ SW620 and SW480 derive from the same patient; SW480 originate from the primary tumor, SW620 from a lymph node metastasis.

${ }^{c}$ Cells analyzed in exponential growth phase.

${ }^{d}$ CD133-positivity on cell surface when stained with AC133 antibody clone; CD133 ${ }^{+} /$CD $_{13}{ }^{-}$fractions gated according to isotype control.

${ }^{\text {e}}$ Staining with $\mathrm{AC} 133$ leads to right shift of entire distribution, ie CD133- ${ }^{-}$and $\mathrm{CD} 133^{+}$subfractions according to footnote $d$ may not necessarily reflect distinct populations.

fDetermined with two different antibodies.

${ }^{g}$ According to colony formation assays.

${ }^{\mathrm{h}}$ Single-dose X-rays.

are still good tools for treatment testing in sophisticated culture systems or in vivo models reflecting the heterogeneous tumor environment.

Supplementary Information accompanies the paper on the Laboratory Investigation website (http://www.laboratoryinvestigation.org)

\section{ACKNOWLEDGEMENTS}

We thank Mrs Marit Wondrak and Mrs Melanie Huether for excellent technical assistance. This work was supported by the German Research Foundation (DFG) through grants KU 971/7-1 and GR 3376/2-1, and the KFO179. OncoRay is funded by the BMBF in the program 'Center for Innovation Competence'. Disclaimer: The authors alone are responsible for the content and writing of the paper.

\section{DISCLOSURE/CONFLICT OF INTEREST}

The authors declare no conflict of interest.

1. Ferlay J, Parkin DM, Steliarova-Foucher E. Estimates of cancer incidence and mortality in Europe in 2008. Eur J Cancer 2010;46: 765-781.

2. Ferlay J, Shin HR, Bray F, et al. Estimates of worldwide burden of cancer in 2008: GLOBOCAN 2008. Int J Cancer 2010;127:2893-2917.

3. Schmiegel W, Pox C, Reinacher-Schick A, et al. S3 guidelines for colorectal carcinoma: results of an evidence-based consensus conference on February 6/7, 2004 and June 8/9, 2007 (for the topics IV, VI and VII). Z Gastroenterol 2010;48:65-136.

4. Rodel C, Arnold D, Becker $\mathrm{H}$, et al. Induction chemotherapy before chemoradiotherapy and surgery for locally advanced rectal cancer: is it time for a randomized phase III trial?. Strahlenther Onkol 2010; 186:658-664.

5. Todaro M, Francipane MG, Medema JP, et al. Colon cancer stem cells: promise of targeted therapy. Gastroenterology 2010;138:2151-2162. 
6. Hermann PC, Bhaskar S, Cioffi M, et al. Cancer stem cells in solid tumors. Semin Cancer Biol 2010;20:77-84.

7. Woodward WA, Sulman EP. Cancer stem cells: markers or biomarkers? Cancer Metastasis Rev 2008;27:459-470.

8. Shipitsin M, Polyak K. The cancer stem cell hypothesis: in search of definitions, markers, and relevance. Lab Invest 2008;88:459-463.

9. Clarke MF, Dick JE, Dirks PB, et al. Cancer stem cells-perspectives on current status and future directions: AACR Workshop on cancer stem cells. Cancer Res 2006;66:9339-9344.

10. Neuzil J, Stantic M, Zobalova R, et al. Tumour-initiating cells vs. cancer 'stem' cells and CD133: what's in the name?. Biochem Biophys Res Commun 2007:355:855-859.

11. Boman BM, Wicha MS. Cancer stem cells: a step toward the cure. J Clin Oncol 2008;26:2795-2799.

12. Huang EH, Wicha MS. Colon cancer stem cells: implications for prevention and therapy. Trends Mol Med 2008;14:503-509.

13. O'Brien CA, Kreso A, Dick JE. Cancer stem cells in solid tumors: an overview. Semin Radiat Oncol 2009;19:71-77.

14. Ricci-Vitiani L, Pagliuca A, Palio E, et al. Colon cancer stem cells. Gut 2008:57:538-548.

15. Visvader JE, Lindeman GJ. Cancer stem cells in solid tumours: accumulating evidence and unresolved questions. Nat Rev Cancer 2008;8:755-768.

16. Dalerba P, Dylla SJ, Park IK, et al. Phenotypic characterization of human colorectal cancer stem cells. Proc Natl Acad Sci USA 2007; 104:10158-10163.

17. Du L, Wang $\mathrm{H}$, He L, et al. CD44 is of functional importance for colorectal cancer stem cells. Clin Cancer Res 2008;14:6751-6760.

18. Haraguchi N, Ohkuma M, Sakashita H, et al. CD133+CD44+ population efficiently enriches colon cancer initiating cells. Ann Surg Oncol 2008;15:2927-2933.

19. O'Brien CA, Pollett A, Gallinger S, et al. A human colon cancer cell capable of initiating tumour growth in immunodeficient mice. Nature 2007:445:106-110.

20. Ricci-Vitiani L, Lombardi DG, Pilozzi E, et al. Identification and expansion of human colon-cancer-initiating cells. Nature 2007;445: 111-115.

21. Dittfeld C, Dietrich A, Peickert S, et al. CD133 expression is not selective for tumor-initiating or radioresistant cell populations in the CRC cell line HCT-116. Radiother Oncol 2010;94:375-383.

22. leta $\mathrm{K}$, Tanaka $\mathrm{F}$, Haraguchi $\mathrm{N}$, et al. Biological and genetic characteristics of tumor-initiating cells in colon cancer. Ann Surg Oncol 2008;15:638-648.

23. Kawamoto $\mathrm{H}$, Yuasa $\mathrm{T}$, Kubota $\mathrm{Y}$, et al. Characteristics of CD133(+) human colon cancer SW620 cells. Cell Transplant 2010;19: 857-864.

24. Ghadimi BM, Sackett DL, Difilippantonio MJ, et al. Centrosome amplification and instability occurs exclusively in aneuploid, but not in diploid colorectal cancer cell lines, and correlates with numerical chromosomal aberrations. Genes Chromosomes Cancer 2000;27: 183-190.

25. Friedrich J, Seidel C, Ebner R, et al. Spheroid-based drug screen: considerations and practical approach. Nature Protocols 2009;4: 309-324.

26. Dallas NA, Xia L, Fan F, et al. Chemoresistant colorectal cancer cells, the cancer stem cell phenotype, and increased sensitivity to insulinlike growth factor-I receptor inhibition. Cancer Res 2009;69: 1951-1957.

27. Sgambato A, Errico F, Caredda E, et al. Divergent expression of CD133 in different studies: The need for a consensus panel?. Int J Cancer 2011;128:2247-2249.

28. Mariotti E, Gemei M, Mirabelli P, et al. The percentage of CD133 + cells in human colorectal cancer cell lines is influenced by Mycoplasma hyorhinis infection. BMC Cancer 2010;10:120.

29. Elsaba TM, Martinez-Pomares $L$, Robins AR, et al. The stem cell marker CD133 associates with enhanced colony formation and cell motility in colorectal cancer. PLoS One 2010;5:e10714.

30. Botchkina Gl, Zuniga ES, Das M, et al. New-generation taxoid SB-T1214 inhibits stem cell-related gene expression in 3D cancer spheroids induced by purified colon tumor-initiating cells. Mol Cancer 2010; 9:192.

31. Baumann $M$, Krause $M$, Thames $H$, et al. Cancer stem cells and radiotherapy. Int J Radiat Biol 20091-12.
32. Gaiser T, Camps J, Meinhardt S, et al. Genome and transcriptome profiles of CD133-positive colorectal cancer cells. Am J Pathol 2011:178:1478-1488.

33. Horst D, Kriegl L, Engel J, et al. CD133 expression is an independent prognostic marker for low survival in colorectal cancer. Br J Cancer 2008;99:1285-1289.

34. Kojima M, Ishii G, Atsumi N, et al. CD133 expression in rectal cancer after preoperative chemoradiotherapy. Cancer Sci 2010;101:906-912.

35. Horst D, Kriegl L, Engel J, et al. CD133 and nuclear beta-catenin: the marker combination to detect high risk cases of low stage colorectal cancer. Eur J Cancer 2009;45:2034-2040.

36. Horst D, Kriegl L, Engel J, et al. Prognostic significance of the cancer stem cell markers CD133, CD44, and CD166 in colorectal cancer. Cancer Invest 2009;27:844-850.

37. Wang Q, Chen ZG, Du CZ, et al. Cancer stem cell marker CD133+ tumour cells and clinical outcome in rectal cancer. Histopathology 2009;55:284-293.

38. Li CY, Li BX, Liang Y, et al. Higher percentage of CD133 + cells is associated with poor prognosis in colon carcinoma patients with stage IIIB. J Transl Med 2009;7:56.

39. Takahashi S, Kamiyama T, Tomaru U, et al. Frequency and pattern of expression of the stem cell marker CD133 have strong prognostic effect on the surgical outcome of colorectal cancer patients. Oncol Rep 2010;24:1201-1212.

40. Ong CW, Kim LG, Kong HH, et al. CD133 expression predicts for nonresponse to chemotherapy in colorectal cancer. Mod Pathol 2010;23: 450-457.

41. Horst D, Scheel SK, Liebmann S, et al. The cancer stem cell marker CD133 has high prognostic impact but unknown functional relevance for the metastasis of human colon cancer. J Pathol 2009;219: 427-434.

42. Saigusa S, Tanaka K, Toiyama Y, et al. Correlation of CD133, OCT4, and SOX2 in rectal cancer and their association with distant recurrence after chemoradiotherapy. Ann Surg Oncol 2009;16:3488-3498.

43. Saigusa S, Tanaka K, Toiyama Y, et al. Clinical significance of CD133 and hypoxia inducible factor-1alpha gene expression in rectal cancer after preoperative chemoradiotherapy. Clin Oncol (R Coll Radiol) 2011; 23:323-332.

44. Saigusa $S$, Tanaka $K$, Toiyama $Y$, et al. Immunohistochemical features of CD133 expression: association with resistance to chemoradiotherapy in rectal cancer. Oncol Rep 2010;24:345-350.

45. Yasuda H, Tanaka K, Saigusa $S$, et al. Elevated CD133, but not VEGF or EGFR, as a predictive marker of distant recurrence after preoperative chemoradiotherapy in rectal cancer. Oncol Rep 2009;22: 709-717.

46. Shmelkov SV, Butler JM, Hooper AT, et al. CD133 expression is not restricted to stem cells, and both CD133 + and CD133 - metastatic colon cancer cells initiate tumors. J Clin Invest 2008;118:2111-2120.

47. Heeschen C, Huber S, Hermann PC. CD133 in cancer stem cells revisited. J Clin Invest 2008;118:2111.

48. Wu Y, Wu PY. CD133 as a marker for cancer stem cells: progresses and concerns. Stem Cells Dev 2009;18:1127-1134.

49. LaBarge MA, Bissell MJ. Is CD133 a marker of metastatic colon cancer stem cells?. J Clin Invest 2008;118:2021-2024.

50. Kemper K, Sprick MR, de Bree M, et al. The AC133 epitope, but not the CD133 protein, is lost upon cancer stem cell differentiation. Cancer Res 2010;70:719-729.

51. Navarro-Alvarez N, Kondo E, Kawamoto $\mathrm{H}$, et al. Isolation and propagation of a human $\mathrm{CD} 133(-)$ colon tumor-derived cell line with tumorigenic and angiogenic properties. Cell Transplant 2010;19: 865-877.

52. Bidlingmaier S, Zhu X, Liu B. The utility and limitations of glycosylated human CD133 epitopes in defining cancer stem cells. J Mol Med 2008; 86:1025-1032.

53. Corbeil D, Roper K, Fargeas CA, et al. Prominin: a story of cholesterol, plasma membrane protrusions and human pathology. Traffic 2001; 2:82-91.

54. Miraglia S, Godfrey W, Yin AH, et al. A novel five-transmembrane hematopoietic stem cell antigen: isolation, characterization, and molecular cloning. Blood 1997:90:5013-5021.

55. Shmelkov SV, Jun L, St Clair R, et al. Alternative promoters regulate transcription of the gene that encodes stem cell surface protein AC133. Blood 2004;103:2055-2061. 
56. Corbeil D, Roper K, Hellwig A, et al. The human AC133 hematopoietic stem cell antigen is also expressed in epithelial cells and targeted to plasma membrane protrusions. J Biol Chem 2000;275: 5512-5520.

57. Taieb N, Maresca M, Guo XJ, et al. The first extracellular domain of the tumour stem cell marker CD133 contains an antigenic gangliosidebinding motif. Cancer Lett 2009;278:164-173.

58. Liao Y, Hu X, Huang X, et al. Quantitative analyses of CD133 expression facilitate researches on tumor stem cells. Biol Pharm Bull 2010;33: 738-742.

59. Platet N, Liu SY, Atifi ME, et al. Influence of oxygen tension on CD133 phenotype in human glioma cell cultures. Cancer Lett 2007;258. 286-290.

60. Blazek ER, Foutch JL, Maki G. Daoy medulloblastoma cells that express CD133 are radioresistant relative to CD133 - cells, and the CD133+ sector is enlarged by hypoxia. Int J Radiat Oncol Biol Phys 2007;67:1-5.
61. Griguer CE, Oliva CR, Gobin E, et al. CD133 is a marker of bioenergetic stress in human glioma. PLoS One 2008;3:e3655.

62. McCord AM, Jamal M, Shankavaram UT, et al. Physiologic oxygen concentration enhances the stem-like properties of CD133 + human glioblastoma cells in vitro. Mol Cancer Res 2009;7:489-497.

63. Brunner TB, Kunz-Schughart LA, Grosse-Gehling P, et al. Cancer stem cells as a predictive factor in radiotherapy. Semin Radiat Oncol 2012 22:151-174.

64. Sgambato A, Errico F, Caredda E, et al. Divergent expression of CD133 in different studies: the need for a consensus panel?. Int J Cancer 2011;128:2247-2249.

65. Yeung TM, Gandhi SC, Wilding JL, et al. Cancer stem cells from colorectal cancer-derived cell lines. Proc Natl Acad Sci USA 2010; 107:3722-3727.

66. Kemper K, Grandela C, Medema JP. Molecular identification and targeting of colorectal cancer stem cells. Oncotarget 2010;1:387-395. 